\title{
Pure species discriminate against hybrids in the Drosophila
} melanogaster species subgroup

4 Antonio Serrato-Capuchina ${ }^{1}$, Timothy D. Schwochert ${ }^{2}$, Stephania Zhang ${ }^{1}$, Baylee Roy ${ }^{1}$,

5 David Peede ${ }^{1}$, Caleigh Koppelman ${ }^{1}$ and Daniel R. Matute ${ }^{1, ~}$ ๆ

12 Tा Correspondence:

13 Biology Department, University of North Carolina, Chapel Hill, North Carolina

14250 Bell Tower Drive, Genome Sciences Building

15 Chapel Hill, NC

16 27510, USA

18 Running title: Hybrids are less attractive than pure species

\section{KEY WORDS}

21 Cuticular hydrocarbons, reproductive isolation, Drosophila, hybrids 


\section{ABSTRACT}

27 Introgression, the exchange of alleles between species, is a common event in nature.

28 This transfer of alleles between species must happen through fertile hybrids.

29 Characterizing the traits that cause defects in hybrids illuminate how and when gene

30 flow is expected to occur. Inviability and sterility are extreme examples of fitness

31 reductions but are not the only type of defects in hybrids. Some traits specific to hybrids

32 are more subtle but are important to determine their fitness. In this report, we study

33 whether F1 hybrids between two species pairs of Drosophila are as attractive as the

34 parental species. We find that in both species pairs, the sexual attractiveness of the F1

35 hybrids is reduced and that pure species discriminate strongly against them. We also

36 find that the cuticular hydrocarbon $(\mathrm{CHC})$ profile of the hybrids is intermediate between

37 the parental species. Perfuming experiments show that modifying the $\mathrm{CHC}$ profile of the

38 hybrids to resemble pure species improves their chances of mating. Our results show

39 that behavioral discrimination against hybrids might be an important component of the

40 persistence of species that can hybridize.

\section{KEY WORDS}

43 Cuticular hydrocarbons, hybrids, reproductive isolation, Drosophila, CHC 


\section{INTRODUCTION}

Species are lineages that are genetically isolated from one another as a result of innate biological differences (Coyne and Orr 2004; Sobel et al. 2010; Harrison 2012; Nosil 2012; Harrison and Larson 2014). Identifying traits that encourage the initial partitioning of the genetic variation into clusters is critical for understanding how species form. In addition to understanding how new species arise, one of the main goals of speciation studies is to understand why species in secondary contact do not collapse into a single population. When speciation is recent, nascent species might have the chance to exchange genes and subsequently merge into a single genetic group. The traits that maintain potentially interbreeding lineages apart are key to understanding why some closely related species persist or collapse (Rosenblum et al. 2012).

Barriers to gene flow can be categorized on whether they occur before or after mating takes place and are deemed either prezygotic or postzygotic barriers, based on their occurrence relative to fertilization of the zygote (Dobzhansky 1937; Sobel et al. 2010). Prezygotic barriers include all the phenotypes of the pure species that preclude the formation of hybrids and range from habitat isolation to incompatibilities between gametes. Among the types of prezygotic isolation, behavioral isolation seems to be ubiquitous in animals (Janicke et al. 2019). Individuals recognize their species (conspecifics) and discriminate against individuals from other species (heterospecifics), based on the recognition of a combination of chemical, auditory, or visual cues (Cady et al. 2011; Vortman et al. 2013; Mérot et al. 2015). Postzygotic barriers include all fitness defects associated with hybrids (Orr and Presgraves 2000; Orr 2005). The most commonly studied forms of postzygotic isolation are hybrid inviability and sterility, in which hybrids fail to develop or even if they develop, do not produce viable gametes, respectively (Orr and Presgraves 2000; Orr 2005).

Other, less extreme, phenotypes can also cause postzygotic isolation. Insect hybrids often show a reduced ability to find proper substrates (Linn et al. 2004; GodoyHerrera et al. 2005; Bendall et al. 2017; Turissini et al. 2017; Cooper et al. 2018). Hybrid birds show reduced ability to perform key tasks, exhibit a decrease in learning spatial tasks, and are worse than their parents at solving novel problems (Delmore and Irwin 2014; McQuillan et al. 2018). Hybrids in flowering plants are often less attractive to 
77 pollinators (Levin 1970; Campbell et al. 1997; Campbell 2004; Ippolito et al. 2004).

78 Reductions of hybrid fitness exist along multiple axes more nuanced than complete

79 infertility or inviability.

80 The sexual attractiveness of hybrids remains largely understudied (but see

81 (Krebs 1990; Gottsberger and Mayer 2007, 2019; Svedin et al. 2008). Behavioral

82 isolation, in the form of mate choice, can also be postzygotic and occur between

83 species and the resulting hybrids (Gottsberger and Mayer 2007, 2019). Since fertile F1

84 hybrids constitute the bridge for genetic exchange between species, assessing the existence of any fitness defects in fertile hybrids constitutes a key component of understanding how much these individuals can facilitate gene exchange between species and determine whether introgression is favored in one of the directions of the cross. A natural prediction is that if species recognition depends on multiple traits, and hybrids show a combination of parental values in those traits, then hybrids might be less attractive to the parental genotypes, reducing hybrid fitness and the potential for

91 introgression.

Cuticular hydrocarbons ( $\mathrm{CHCs}$ ) are fatty acid-derived apolar lipids that accumulate on the body cuticle of insects (reviewed in (Singer 1998; Ferveur 2005;

94 Blomquist and Bagnères 2010)). The function of CHCs is twofold, affecting survival and 95 reproduction (Chung and Carroll 2015). First, CHCs help regulate the osmotic balance 96 within insect bodies, which makes them important for adaptation to water-limited areas.

97 Second, CHCs are important for chemosensory communication among individuals. As a

98 result, divergence in $\mathrm{CHCs}$ can lead to prezygotic isolation among species, both in

99 terms of habitat separation and of mate choice (reviewed in (Smadja and Butlin 2009).

100 Long-chained CHCs are usually more important in waterproofing, whereas shorter-chain

$101 \mathrm{CHCs}$, which tend to be more volatile $\mathrm{CHCs}$, can be involved in sexual signaling over

102 short distances (Hadley 1981; Gibbs 1998; Ferveur and Cobb 2010; Gibbs and

103 Rajpurohit 2010). Longer chain CHCs can also act as contact pheromones in multiple

104 insect species (Venard and Jallon 1980; Ingleby 2015). Closely-related species

105 commonly differ in the composition of CHCs (Shirangi et al. 2009); these differences

106 reduce the likelihood of matings between individuals from different species, effectively

107 serving as a barrier to gene flow. Despite the robust research program reporting the 
108 differences in CHC composition between different species pairs (e.g., (Gleason et al.

109 2009; Sharma et al. 2012; Chung and Carroll 2015; Dembeck et al. 2015; Denis et al.

110 2015; Combs et al. 2018)), little is known regarding changes of CHC composition in F1

111 hybrids and how these changes might affect the attractiveness of hybrids to pure

112 species individuals.

113 Drosophila species pairs in which hybridization yields fertile progeny, and show

114 evidence of introgression in nature, are ideal systems to study barriers to gene flow that

115 contribute to species persistence in nature. In this report, we studied whether

116 interspecific hybrids are less attractive than pure-species counterparts to pure-species

117 individuals. We focus on two species clades that produce fertile female progeny and

118 show evidence of gene exchange in nature, the Drosophila simulans and D. yakuba-

119 species complexes. The Drosophila simulans-species complex consists of three sister

120 species: D. simulans, D. sechellia, and D. mauritiana. Drosophila simulans can produce

121 fertile F1 females with both $D$. sechellia and $D$. mauritiana; the species triad diverged

122 within the last 0.2 million years (Kliman et al. 2000; Schrider et al. 2018; Meany et al.

123 2019). All species pairs in this group show evidence of introgression (Garrigan et al.

124 2012; Brand et al. 2013; Meiklejohn et al. 2018; Schrider et al. 2018), and in the case of

125 D. simulans and $D$. sechellia, the two species form a hybrid zone in the central islands

126 of the Seychelles archipelago (Matute and Ayroles 2014). The D. yakuba-species

127 complex is also composed of three species: $D$. yakuba, D. santomea, and D. teissieri.

128 Drosophila yakuba and $D$. santomea diverged between 0.5 and 1 million years ago,

129 while the dyad diverged from their sister $D$. teissieri approximately 3 million years ago

130 (Bachtrog et al. 2006; Turissini and Matute 2017). Like the D. simulans complex, hybrid

131 crosses involving $D$. yakuba with $D$. santomea/D. teissieri produce sterile males and

132 fertile females (Lachaise et al. 2000; Coyne et al. 2004). Notably, D. yakuba forms

133 stable hybrid zones with both D. santomea (Llopart 2005; Llopart et al. 2009; Matute

134 2010; Comeault et al. 2016) and D. teissieri (Cooper et al. 2018; Turissini and Matute

1352017 ) in the Afronesian islands of São Tomé and Bioko, respectively.

136 In this study, we report that Drosophila hybrids_both male and female-are less

137 likely than pure species individuals to be pursued and accepted in mating by pure

138 species. The $\mathrm{CHC}$ composition of female hybrids is largely intermediate between 
139 parentals. Hybrid females perfumed as pure species show higher attractiveness to pure

140 species females. Additionally, pure species perfumed as F1s show reduced

141 attractiveness. These results suggest that hybrids are less sexually attractive than

142 conspecifics, likely due to differences in $\mathrm{CHC}$ composition. Finally, we quantify $\mathrm{CHC}$

143 profiles of pure species and their hybrids to test how their pheromonal composition

144 changes within the species complex. Our results suggest that nuanced fitness

145 reductions in hybrids can be important to determine whether hybrids facilitate gene

146 transfer between species in nature.

147

148 


\section{METHODS}

\section{Stocks}

152 Our goal was to compare the attractiveness (mate choice tests) and $\mathrm{CHC}$ content of F1 153 hybrids to their pure species parents. To this end, we used isofemale lines for all our 154 experiments. We used a single isofemale line for each of the four species we studied.

155 Please note that there is variation between isofemale lines within species (Sharma et al. 156 2012; Denis et al. 2015) and extensive phenotypic plasticity in CHCs (Thomas and 157 Simmons 2011; Rajpurohit et al. 2017; Otte et al. 2018). Details for each of these lines 158 have been previously published. For $D$. simulans, we used the line Riaba, which was 159 collected in 2009 on the island of Bioko (Serrato-Capuchina et al. 2020). For $D$.

160 mauritiana, we used R50, a line collected on the island of Rodrigues in 2009 (Brand et 161 al. 2013). For $D$. yakuba, we used ym5.02, a line collected in the midlands of the island 162 of São Tomé in 2018. Finally, for $D$. santomea, we used Thena7, a line collected at the 163 edge of Obó national park on the island of São Tomé (Comeault et al. 2016). All lines 164 were kept in cornmeal $30 \mathrm{~mL}$ vials.

\section{Fly rearing and virgin collection}

167 During the experiments reported here, we kept all isofemale lines in $100 \mathrm{ml}$ plastic

168 bottles with standard cornmeal/Karo/agar medium at room temperature. Once we saw 169 larvae on the media, we transferred the adults to a different bottle and added a squirt of $170 \quad 0.5 \%$ V/V solution of propionic acid and a pupation substrate (Kimberly Clark, Kimwipes 171 Delicate Task; Irving, TX) to the media. Approximately 10 days later, virgin pupae start eclosing, at which point we began collecting virgins. We cleared bottles every 8 hours

173 and collected the flies that emerged during that period. This procedure ensured that flies

174 had not mated, as they are not sexually mature. We separated flies by sex and kept

175 them in sex-specific vials in groups of 20 individuals.

177 Hybrid production

178 To make hybrids, we mixed a group of females and males (collected as described 179 immediately above) in $30 \mathrm{~mL}$ vials with freshly yeasted food. All flies were 3-7 day old 
180 virgins. To increase the likelihood of mating, we mixed flies in a 1:2 female to male ratio.

181 Vials were inspected every two days to see if there were larvae in them. Once we

182 observed larvae in the vials, adults were transferred to a new vial, and the previous vial

183 was tended with $0.5 \%$ propionic acid and a pupation substrate as described above. If,

184 after a week, a vial had not produced progeny, the flies were transferred to a vial with

185 fresh food. Virgin hybrids were collected in the same way described above and stored in

186 sex-specific vials until further experimentation. To further ensure the identity of the

187 hybrids, we extracted the testes of a subset of the F1 males for each cross $(\mathrm{N}=20)$ to

188 score their fertility using methods previously published, namely, scoring for motile sperm

189 (Turissini et al. 2015). F1 hybrids in all the possible crosses are sterile as they do not

190 produce motile sperm (Coyne et al. 2004; Moehring et al. 2004; Turissini et al. 2015). In

191 all instances reporting F1 hybrids, the genotype of the mother is listed first, and the

192 genotype of the father, second.

194 Mate choice tests

195 Effect of markings on female attractiveness: Our first set of experiments involved a

196 setup with one male and four females for the male to choose. As a proxy of the

197 attractiveness of each female in the vial, we measured the time the male spent courting

198 each of the females. These male attractiveness experiments required labeling the

199 females to distinguish them from each other. We marked the females in two different

200 ways. First, we clipped their wings. To do this marking, we anesthetized flies at

201 collection ( eight hours after hatching) and cut a nick in their wing in one of four ways:

202 horizontal on the right wing, horizontal on the left wing, vertical on the right wing, or

203 vertical on the right wing. Second, we placed the marked flies in dyed food two hours

204 before matings to color their abdomens. We used three different colors and left one of

205 the genotypes unlabeled for a total of four abdominal colors. We used a combination of

206 both markings for a total of 16 potential combinations.

207 We studied the potential effect that these markings had on female attractiveness

208 by doing mate choice experiments with a conspecific male and four females of the same

209 genotype marked differently. To study the effect of single markings, we placed four

210 females from the same genotype marked differently (either colored or clipped), and a 
211 conspecific male in a $30 \mathrm{~mL}$ vial. We observed the group for one hour. We then let the

212 male choose among the four females and scored the identity of the mated female. First,

213 we assessed whether colored abdomens led to a change in attractiveness by labeling

214 the females only with colored food (100 females per species). Second, we assessed

215 whether the clipping procedure led to a change in attractiveness (100 females per

216 species). For these two experiments (each with four types of marking), the proportion of

217 chosen females should follow a 1:1:1:1 expectation as long as the marking treatment

218 has no effect on the attractiveness of the females. We used Pearson's $X^{2}$ test to test

219 these two hypotheses (function chisq.test, library 'stats', (R Core Team 2016)).

$220 \quad$ Finally, we studied whether the double-marking approach affected the female

221 attractiveness in conspecific matings using mass matings. We labeled females with the

222 two markings (color and clipping; 16 combinations). We then put 320 flies in a mesh

223 cage (24.5 cm x $24.5 \mathrm{~cm} \times 24.5 \mathrm{~cm}$; www.bugdorm.com): 160 males and 10 females of

224 each marking. We observed the cage for one hour and aspirated pairs that were mating

225 and scored the marking of the male. We ran this experiment three times for each of the

226 species for a total of 12 cages (480 males per species). Please note this experiment is

227 different from our other choice experiments (described above) and since there are more

228 males per cage than in a $30 \mathrm{~mL}$ vial, there might be higher chance of reproductive

229 interference among males (Matute 2014). Nonetheless, these results inform if any

230 marking scheme grossly affects female attractiveness. We compared the proportions of

231 mated females with the expectation of a uniform mating rate using a Pearson's $X^{2}$ test

232 (function chisq.test, library 'stats', (R Core Team 2016).

233 Additionally, we ran a smaller experiment in which we studied the female

234 attractiveness of doubly-marked females, measured as the time the males spent

235 courting each female. We placed four marked females in a $30 \mathrm{~mL}$ vial with a pure

236 species conspecific male and scored the time that the male spent courting each type of

237 female as described above. The marking of each female was randomly assigned. We

238 did this for the four species and 24 replicates per species. The metric of attractiveness

239 was scored by two different scorers. We only observed one trial at once. First, we

240 assessed whether the scorer had an effect by fitting a linear model in which species and

241 scorer were the effects and the observed time was the response (function Im, R library 
242 stats; (R Core Team 2016)). Since we found no strong effect of the observer, all further 243 observations involved only one observer.

244 Second, and using the same dataset, we studied whether the double-markings

245 had an effect on the attractiveness of each female. We fitted a linear model (function Im,

246 R library stats; (R Core Team 2016)) where the proportion of time that each male spent

247 courting each of the four types of females was the response and the two types of

248 markings were the fixed effects. We included an interaction term between markings.

Female attractiveness in male choice experiments: To compare F1 hybrids vs pure-

251 species female attractiveness, we used mate choice experiments in which a pure

252 species virgin male had the choice of four different females, a virgin hybrid F1 female

253 from each reciprocal cross, and one virgin female from each of the parental species in a

$25430 \mathrm{~mL}$ vial with cornmeal food (i.e., five flies per mating assay). Since F1 females and

255 pure species look similar, we marked them as described above. Even though our

256 experiments show that these marking schemes have no effect on male choice (See

257 below, Figures S1-S3), we randomized the genotype and the marking scheme to

258 minimize any potential effect of the markings. The five flies (four females and one male)

259 were placed in a vial within one minute and were not moved for the next two minutes.

260 For the next 30 minutes, we observed what female the male approached and scored

261 active courting behavior defined as the time that the male spent following, courting, and

262 attempting to mount each type of female. We observed only one male at a time. We

263 then scored an index of attractiveness for each female defined as:

$$
\text { index of attractiveness }_{i}=\frac{\text { time spent courting female }}{i}
$$

We observed 300 males from 15 different families per species for a total of 1,200 males (i.e., 20 males $\times 15$ families $\times 4$ species). To analyze the metric of

269 attractiveness of each female (described above), and whether males courted 270 conspecific and hybrid females at different rates, we compared the proportion of time 271 that each male spent courting each of the four types of females using a linear mixed 
272 model (LMM; function Ime, R library nIme; (Pinheiro J, Bates D, DebRoy S 2017)) where

273 the identity of the female was a fixed effect and the block and marking were considered

274 random effects. We also did posthoc pairwise comparisons using the function Ismeans

275 (R library Ismeans, (Lenth and Hervé 2015; Lenth 2017)).

276

277 Male mating rates in non-choice experiments: Next, we studied the mean mating rates

278 of hybrid males using a non-choice mating experiment (one female and one male). We

279 used this design because it allowed us to assess whether a female accepted or rejected

280 a given male while measuring the effort to mate excerpted by the male. To set up non-

281 choice experiments, we placed a 4 day-old virgin female and a 4 day-old virgin male in

282 a $30 \mathrm{~mL}$ plastic vial with cornmeal food. We observed the pair for one hour. For each

283 genotype of pure-species female, we did mating experiments with four types of males:

284 conspecific, heterospecific, and the two reciprocal F1 males. We setup ten blocks of

285 matings (i.e., days of experimentation) for each cross, each with 100 matings, for a total

286 of 1,000 matings per cross. We watched 200 matings at a time, all of them with the

287 same female genotype (50 of each type of cross). We did two matings in a single day

288 which yielded 100 females for each type of cross per day. Since there were only two

289 flies per vial (one female and one male), there was no need to mark either sex.

290 For each type of mating, we scored three characteristics of the mating. First, we

291 recorded whether the female accepted the male. To compare the likelihood of mating,

292 we fitted a logistic regression. Females that mated were considered successes, females

293 that did not were considered failures. The only fixed effect was the genotype of the male

294 while the experimental block was considered a random effect. We used the function

295 glmer (library Ime4 (Bates et al. 2015)) for these analyses. To assess significant of the

296 fixed effect, we used a type-III ANOVA (function Anova, library car; (Fox and Sanford

297 2011; Fox and Weisberg 2019)). We also measured the significance of the male effect

298 using a likelihood ratio test comparing the model described above with one of no male

299 effect (function Irtest, library Imtest; (Hothorn et al. 2011)). We compared the proportion

300 of accepted males in the different crosses using a Tukey test using the function Ismeans

301 (library Imtest, (Hothorn et al. 2011)). 
Second, we recorded the copulation latency for the different types of crosses, which also serves as an additional proxy of male attractiveness (i.e., more attractive males have shorter latencies, (Ejima and Griffith 2007)). Since the likelihood of the different matings differs, the number of observations differs among cross types (See Results). To compare latency and duration among cross-type, we used the function $I m$

307 (library stats, (R Core Team 2016)) and fitted a one-way ANOVA where the latency was 308 the response, and the cross was the only fixed factor. We also did posthoc pairwise comparisons using a Tukey HSD test (function glht, library 'multcomp' (Hothorn et al. 2008)). We used an identical approach to study heterogeneity in copulation duration.

We also recorded whether the male was courting the female every two minutes

312 (the time that it took to inspect the 200 males in the assay). Every time window in which

313 the male was observed, courting was categorized as an effort to mate. To study male

314 effort by genotype, we focused on pairs that mated. Since one might observe higher

315 efforts on longer matings (i.e., higher latencies), we used the number of efforts per unit

316 of time, a ratio between the number of efforts and the mating latency. We compared this

317 metric across genotypes with a linear model where the metric was the response, and

318 the type of cross was the fixed factor (function Im, library stats).

\section{CHC quantification}

322 Studied CHCs: For D. simulans, D. mauritiana and their hybrids, we measured the 323 concentrations of $n$-Heneicosane, 11-cis-Vaccenyl Acetate, Tricosane, 7(Z)-Tricosene, 324 7-Pentacosene, 7(Z),11(Z)-Heptacosadiene, and 7(Z)-Nonacosadiene. For D. yakuba, 325 D. santomea, and their hybrids, we measured the same CHCs. These CHCs

326 encompass the primary CHC composition in both the simulans (Sharma et al. 2012;

327 Ingleby et al. 2013) and yakuba species complex (Mas and Jallon 2005; Denis et al. 328 2015).

$330 \quad$ CHC standard curves: To quantify the seven $\mathrm{CHCs}$ listed above, we purchased 331 standards of the seven compounds. The catalog numbers are listed in Table S1. We did 332 gas chromatography (GC) using an Agilent 7820A gas chromatography system 
333 equipped with a FID detected and a J\&W Scientific cyclosil-B column $(30 \mathrm{~m} \times 0.25 \mathrm{~mm}$

334 ID $\times 0.25 \mu \mathrm{m}$ film) to characterize the elution time of the standards. GC provides 1) the

335 retention time of each $\mathrm{CHC}$ and 2) the peak integration ratio between the known

336 quantities of the target $\mathrm{CHC}$ and that of internal standard permitting quantification of

337 target $\mathrm{CHCs}$ from fly extracts. First, we measured the retention times for each of the

338 CHCs (Table S1). This allowed us to identify specific $\mathrm{CHC}$ compounds in the fly extracts

339 based on their retention time. Second, we diluted each of the compounds to concentrations of $150 \mu \mathrm{M}, 100 \mu \mathrm{M}, 75 \mu \mathrm{M}, 50 \mu \mathrm{M}$, and $25 \mu \mathrm{M}$ using hexacosane (1mM)

341 as an internal standard. We measured the signal ratio between the target $\mathrm{CHC}$ and that 342 of the internal standard. For each compound, we fit a linear model using the function $I m$ 343 (library 'stats') with the concentration of the $\mathrm{CHC}$ as the response and the ratio of the 344 peak height to the internal standard as the sole continuous factor. Figure S4 shows the 345 seven regressions for each $\mathrm{CHC}$.

347 CHC extraction from individual flies: CHCs from single virgin flies were extracted by 348 placing individuals (aged 4-7 days) in a glass disposable culture tube and submerging in $3491 \mathrm{~mL}$ of a solution of heptane and hexacosane (internal standard; $\mathrm{mM}$ ) for 3 minutes 350 with light shaking. The extract was filtered through glass wool prior to GC analysis. All 351 extractions were completed between 2:00 pm and 4:00 pm, with GC analysis taking 352 place as quickly as possible following the extraction procedure. Measurements were 353 done in the same GC machine described above. The method used to separate $\mathrm{CHCs}$ 354 present in fly extracts consisted of holding the GC oven at $150{ }^{\circ} \mathrm{C}$ for $5 \mathrm{~min}$, then 355 ramped at $5^{\circ} \mathrm{C} / \mathrm{min}$, held for $10 \mathrm{~min}$, then ramped again at $10^{\circ} \mathrm{C} / \mathrm{min}$, and held for 15 $356 \min$. The number of samples for each genotype ranged between six and twenty-one and 357 is listed in Table S2.

359 CHC quantification: We integrated the peaks using the Agilent 7280A software for each

360 GC graph from individual extractions, and transformed the area-under-curve (AUC) 361 across each corresponding retention time to $\mathrm{CHC}$ amount using the slopes of the

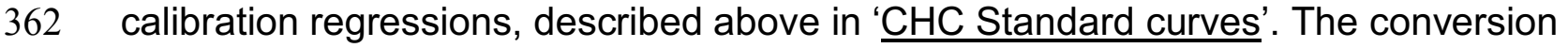
363 followed the transformation: 
$\mathrm{mM}$ amount $=($ focal-CHC AUC/internal-standard $\mathrm{AUC}) \times$ factor $_{\mathrm{i}}$

where factor ${ }_{i}$ represents the slope for each given $\mathrm{CHC}$.

Analyses: To compare the $\mathrm{CHC}$ blends among pure species and $\mathrm{F} 1$ hybrids in each species group, we generated a principal component analysis (PCA) for each species group. We used the function prcomp (library stats) to calculate the PCA loadings and visualized the results with the function fviz_pca_ind (library factoextra, (Kassambara and Mundt 2017)). The distribution of each genotype was plotted using the option ellipse.type with a multinomial distribution. In both cases, PC1 explained the vast majority of the variance (see results), and we only used that PC to study heterogeneity among genotypes. We fitted a One-way ANOVA with PC1 as a response and genotype as the only factor using the function Im (library 'stats', (R Core Team 2016)). We then performed pairwise comparisons using a Tukey HSD test using the function glht (library 'multcomp', (Hothorn et al. 2008)).

\section{Perfuming assays}

Hybrids show lower success mating compared to pure species individuals, and show $\mathrm{CHC}$ profiles that differ from both parentals (See results). We tested whether there was a connection between these two results by changing the $\mathrm{CHC}$ profile, through perfuming, of hybrid and pure-species flies and then measuring their attractiveness. Perfuming consisted of placing a single focal female in a vial with 10 perfuming-females for 4 days, allowing time for the $\mathrm{CHC}$ profiles to homogenize. We describe these two sets of experiments as follows.

First, we did choice experiments with perfumed flies involving hybrid females. We

391 focused on hybrid females as, unlike hybrid males, they are fertile and thus can serve

392 as a bridge for gene exchange between species. The choice experiments involved a

393 single pure-species male, and he had the choice to mate with one of three hybrid

394 females (i.e., all with the same genotype), one that was not perfumed, one that was 
395 perfumed with one of the parents, and one with the other parent. We only used one of

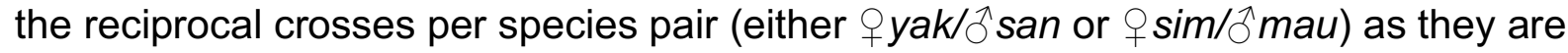
much easier to produce than the reciprocal direction (Yukilevich 2012; Lachaise et al. 1986; Turissini et al. 2018). All perfuming experiments are similar, so we only describe one of them. To assess whether perfuming F1 ( $q \operatorname{sim} \times \stackrel{1}{\mathrm{~m}} \mathrm{mau}$ ) females changed their attractiveness to $D$. mauritiana males, we perfumed $\mathrm{F} 1$ ( $9 \mathrm{sim} / \widehat{\jmath} \mathrm{mau}$ ) females with $D$.

401 mauritiana females, F1 (q sim/ Îmau) females with $D$. simulans females, and F1

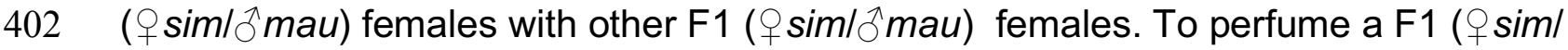

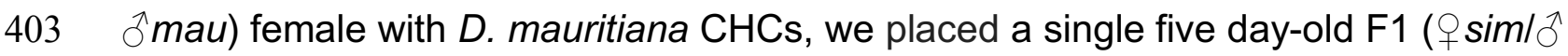

$404 \mathrm{mau}$ ) female with 10 D. mauritiana females from the same sex for four days. The F1

405 (q $\operatorname{sim} / \widehat{m a u})$ female perfumed with $D$. simulans was placed with $D$. simulans females

406 instead but followed the same approach. The third female, was a F1 ( $q$ sim/ $\mathrm{mau}$ ) that

407 was 'perfumed' with other F1 CHCs by raising it with other ten F1 females of the same

408 genotype. This procedure should not change the $\mathrm{CHC}$ profile of the female, but it

409 exposes the focal female to the same rearing density of the other perfumed females.

410 Females were marked by feeding them colored food and clipping their wings (see

411 above). The three types of females were marked by labeling their abdomens and

412 clipping their wings as described above. After four days, we removed each of the focal

413 females from their 'perfuming vials' by aspiration (no $\mathrm{CO}_{2}$ anesthesia) and placed them

414 in an $30 \mathrm{~mL}$ vial with fly food. We also added a virgin pure species male with the three

415 perfumed F1 females. We watched the vial for one hour and scored the identity of the

416 female the male chose for mating. The expectation was that if perfuming had no effect

417 on the attractiveness of the hybrid females, then the males should choose randomly and

418 the choice should follow a 1:1:1 ratio. On the other hand, if the CHC blend on the

419 hybrids reduces their attractiveness, then perfuming them like pure species should lead

420 to an increase in their attractiveness (i.e., they should be more likely to be chosen by

421 pure species male). We observed 50 flies per genotype in each block (i.e., experiments

422 ran on the same day) and did six blocks per type of assay for a total of 300 per male 423 genotype.

424 Second, we did similar experiments for each of the pure species and studied 425 whether perfuming pure-species females with heterospecific, or hybrid CHC blends, 
426 reduced their attractiveness. We placed a pure species male with three conspecific

427 females, one that was perfumed with her conspecifics, one that was perfumed with F1

428 hybrids, and one that was perfumed with the other species. The approaches of this set

429 of experiments are identical to the ones described above for the F1 hybrids. The

430 expectation was that if the heterospecifics or hybrid $\mathrm{CHC}$ blends are less attractive than

431 the conspecific blend, then the females perfumed with these blends should be less

432 attractive. We did 50 replicates for each type of male per block and six blocks, which

433 lead to 300 observations per male genotype.

434 The analyses for both perfuming experiments, hybrids, and pure-species, are the

435 same. To evaluate the 1:1:1 expectation, we used a Pearson's $X^{2}$ test (function

436 chisq.test, library 'stats', (R Core Team 2016)). If the perfuming affected the outcome of

437 the mating (i.e., the mated female), then the ratio of mated females from each treatment

438 will differ from 1:1:1. To evaluate which pairs differed from each other, we used an

439 Approximative Two-Sample Fisher-Pitman Permutation Test (function 'oneway_test',

440 library 'coin'; (Hothorn et al. 2006)).

441 A sample of these perfumed flies_from both perfumed pure species and

442 perfumed $\mathrm{F} 1 \mathrm{~s}$ - was scored for $\mathrm{CHC}$ profiles as described above (See $\underline{\mathrm{CHC}}$

443 quantification). The number of samples for each treatment ranged between four and

444 twenty-one and is listed in Table S2. 


\section{RESULTS}

Pure species discriminate against hybrids

448 First, we studied whether marking females had an effect on mate choice. We found that 449 individual markings have no effect on the male choice (Figures S1-S2, Tables S3-S4).

450 Double markings caused no deviations from the expectation of uniform male choice in 451 mass matings either (in all cases $X^{2}<6.096$, $\mathrm{df}=15, \mathrm{P}>0.9$, Table S5).

Since markings did not affect female attractiveness, we used them in matings where males had the choice of conspecific, heterospecific, and reciprocal hybrid

454 females. Our goal was to determine whether pure species males discriminated against

455 hybrid females. For all the four genotypes, the proportion of assays that yielded a mated 456 male was over $80 \%$ (Figure 1A-D). As expected, pure species males from any of the 457 four assayed species overwhelmingly preferred females from their own species over 458 any other type of female-including hybrids - In all assays, over $95 \%$ of the mated 459 males chose conspecific females. The preference for conspecifics is consistent with 460 previous results, which suggest that males show a strong preference for conspecific 461 females and discriminate against heterospecific females (Shahandeh et al. 2018). Besides the outcome of the matings in mass matings, we also scored the effort 463 males spent courting each type of female when they have four females to choose from. 464 In choice experiments where the four females were conspecifics, we found no effect of 465 the markings (Table S6, Figure S3) or the scorer (Figure S5) on female attractiveness. 466 In experiments where males had the choice of mating with conspecific, heterospecific, 467 and hybrid females, we found that the amount of time pure-species males spent 468 courting each type of female differed depending on the type of female (Figure 1;LMM, 469 female genotype effect $F_{3,957}=6,021.967, P<1 \times 10^{-10}$ for all four types of males).

470 Males spend much more time courting conspecific females than any other genotype 471 (Figure 1E-H, Table S7). In general, F1 hybrid females were slightly less attractive than 472 heterospecific females. Differences between reciprocal F1s were minimal (Figure 1, 473 Table S7). These joint results indicate that pure species parental males are less likely 474 to mate with F1 females if they have the choice of mating with a conspecific or 
475 heterospecific and that discrimination against hybrid females might act as an important component of reproductive isolation.

$477 \quad$ Next, we studied the frequency of mating of pure species females with

478 conspecific, heterospecific, and hybrid males in non-choice mate experiments. For all

479 female genotypes, the frequency of matings with heterospecific or hybrid males is much

480 lower than the frequency of matings with conspecific males (Figure 2; LMM male

481 genotype effect: $\mathrm{LRT}>1,747.8 ; \mathrm{P}<1 \times 10^{-10}$ in all cases, Table S8). In D. yakuba, $D$.

482 santomea, and $D$. simulans, matings with hybrid males are less likely to occur than

483 matings with heterospecific males (in D. mauritiana they are equally likely; Table S9).

484 Lower rates of mating between pure-species females and hybrid males can be

485 interpreted as lower male attractiveness, lower interest in matings by the males, or a

486 combination of both. We measured a proxy of the effort invested by conspecific,

487 heterospecific, and hybrid males in each type of cross in cases where mating took

488 place. We find that the effort from males in heterospecific matings is generally lower

489 than that in conspecific crosses (Figure 3). The effort in mating from hybrid males is

490 similar to that shown by heterospecific males (Figure 3, Table S10). These results

491 suggest that hybrid males have a lower interest in mating with either type of pure

492 species female than pure species males do. They also show that even though hybrid

493 males try to mate at similar rates as males in heterospecific crosses, their success rates

494 are lower; thus, suggesting that the attractiveness of hybrid males is lower than that of

495 either pure species males.

496 We measured two additional characteristics of mating in these no choice

497 experiments: copulation latency and copulation duration. When females mate with

498 heterospecific or hybrid males in non-choice experiments, the matings take much longer

499 to start than in non-choice conspecific matings. Latency is similar in matings with

500 hybrids or with heterospecifics (Table 1). Mating duration is also longer in conspecific

501 than in heterospecific of hybrid-male matings (Table S11). Altogether, these results are

502 in line with the idea that the reduced mating rates of hybrid males are the result of lower

503 interest in mating from the hybrids (behavioral sterility) and female discrimination

504 against them. Since hybrid males in the two studied pairs are sterile, they cannot

505 interbreed with the parental females; the fact that they are less likely to be accepted by 
506 the females is much less relevant as a reproductive barrier than their complete hybrid

507 sterility. Nonetheless, this result is qualitatively similar to the pattern for female

508 acceptance rates to different genotypes of males and suggests that the discrimination of

509 pure species against hybrids is a phenomenon that applies to both sexes.

511 Hybrids show different CHC profiles than pure species

513 We measured the $\mathrm{CHC}$ composition of pure species and hybrids for two of the species

514 pairs we studied, D. yakuba/D. santomea and D. simulans/D. mauritiana. We focused

515 on females as they are fertile and can produce advanced intercrosses, whereas males

516 cannot. Since the effect of CHCs in mating attractiveness is a joint one across multiple

517 CHCs (Mas and Jallon 2005; Liimatainen and Jallon 2007; Grillet et al. 2012) and not

518 one of individual CHCs, we plotted the distribution of the parental species and each of

519 the F1 hybrids in a principal component analysis for each species pair (Figure 4).

520 Tables S12 and S13 show the PCA loadings, and Figures S6 and S7 show the

521 eigenvectors. The results for both species pairs are similar. In the case of $D$. yakuba/D.

522 santomea females, we found that PC1 explains $97 \%$ of the variance. PC2 explains

$5231.4 \%$ of the variance. In the case of $D$. simulans/D. mauritiana females, we found that

524 PC1 explains $76 \%$ of the variance. PC2 explains $22.5 \%$ of the variation. For both

525 species pairs, PC1 differentiates between the two pure species; while PC2 seems to be

526 associated with variance within genotypes. The $\mathrm{CHC}$ profile of the pure species is

527 mostly disjointed in both species pairs. F1 hybrid females appear mostly as an

528 intermediate between the two parental species, although some individuals seem to

529 show transgressive patterns of segregation, consistent with other observations in other

530 Drosophila hybrids (Coyne et al. 1994; Gleason and Ritchie 2004).

$531 \quad$ Next, we studied whether there is variation in PC1 among genotypes. We found

532 extensive heterogeneity among genotypes in both species pairs (Table 2). Drosophila

533 yakuba and $D$. santomea differed, suggesting differences in their $\mathrm{CHC}$ blend. This is

534 consistent with previous reports which showed differentiation in the CHC blends

535 between this two species (Mas and Jallon 2005). The two reciprocal F1 females, F1

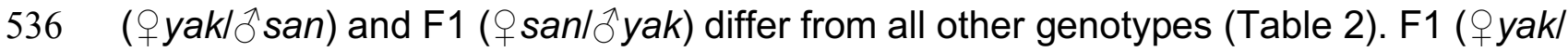


537 șan) are broadly distributed along PC1 and PC2. Results were similar when we

538 studied PC1 in the sim/mau genotypes (Table 2). (Note that we did not measure CHCs

539 in F1 (†̣maulōsim) hybrids.) All measured genotypes differ from each other (Table 2).

$540 \mathrm{~F} 1$ ( 9 simlômau) hybrids showed a large spread on PC1. These results and the

541 distribution of the $\mathrm{CHC}$ blend in the PCAs indicate that there are some differences

542 between hybrids and pure species, but also that-at least some-F1s show a large

543 variance in their $\mathrm{CHC}$ blends.

\section{Perfuming assays}

546 Since F1 individuals are less attractive to pure species than conspecifics, and their $\mathrm{CHC}$ 547 profiles are different from their pure species counterparts, we hypothesized that

548 modifying the $\mathrm{CHC}$ of the hybrids to be more akin to the profile of the pure species

549 would increase their chance of mating. We also hypothesized that modifying the $\mathrm{CHC}$

550 profile of pure species to resemble the $\mathrm{CHC}$ profile of hybrids would decrease their

551 mating success.

$552 \quad$ First, we studied whether the perfuming treatment affected the CHC profile of

553 perfumed flies. We focused on the simulans/mauritiana species pair. Figure 4 shows a

554 PCA of the CHCs of pure D. simulans, pure D. mauritiana, and the reciprocal F1s (as

555 shown in Figure 4) but also shows the CHC pattern of perfumed $D$. simulans (Figure

556 4A), perfumed D. mauritiana (Figure 4B), and perfumed F1 females (Figure 4C) in PCA

557 biplots. Tables S14-S16 show the loadings of the PCAs, and Figures S8-S10 show the

558 eigenvectors. In the three perfuming experiments, we observed that perfumed

559 individuals had a $\mathrm{CHC}$ profile that was intermediate between their genotype and the

560 population to which they were exposed during the perfuming phase (Figure 4, Table 3).

561 These results suggest that perfuming treatments are an effective way to modify, but not

562 fully replace, the $\mathrm{CHC}$ of a focal fly.

$563 \quad$ Next, we perfumed F1 and pure-species females and studied their attractiveness.

564 The effect of perfuming F1 females was strong for all species, as all male-choice assays

565 showed deviations from a 1:1:1 ratio (expected if there was random-choice; Figure 5);

566 the three types of females (i.e., the type of perfuming treatment) showed differences in

567 attractiveness in all assayed F1 genotypes. F1 females that had been perfumed as 
568 pure-species females were more attractive to pure species males, as long as the 569 perfuming treatment and the male species matched (Table S17). F1 females that had

570 been perfumed as other F1s showed a level of attractiveness as expected by random

571 choice (i.e., they were chosen $1 / 3$ of the time). Note that the only difference between

572 these F1 females is whether they were perfumed or not, as their genotype is identical.

573 These results indicate that modifying the $\mathrm{CHC}$ profile of $\mathrm{F} 1$ females changes their

574 chances of being courted by a pure species male. The blend of $\mathrm{CHC}$ in hybrids is an

575 important component of their reduced sexual attractiveness to pure species males,

576 which ultimately affects the possibility they might serve as a bridge for gene flow

577 between species.

$578 \quad$ Finally, we did choice mating experiments that involved perfuming pure species

579 females. As occurred with the F1 hybrid perfuming experiments, perfuming lead to

580 differences in the pure-species females attractiveness. Even though treatments differ

581 among themselves, no treatment differed from the $1 / 3$ expectation, suggesting relatively

582 mild effects of the perfuming treatment. Females perfumed with the CHCs of their

583 conspecifics were the most attractive type to their conspecific males (Figure 6, Table

584 S18). Pure species females perfumed as heterospecifics showed the lowest level of

585 mating, suggesting that their $\mathrm{CHC}$ blend is less attractive to pure species males. Pure

586 species females perfumed with the $\mathrm{CHC}$ blend of the hybrids show a decrease

587 compared with pure-species perfumed with their native blend and a level of

588 attractiveness similar to that of pure-species females perfumed with the heterospecific

589 blend. These results are consistent with the possibility that the $\mathrm{CHC}$ blend in hybrid

590 females is less attractive to both pure species. The results from our perfuming

591 experiments suggest that hybrid $\mathrm{CHC}$ blends are deleterious as they reduce the fitness

592 of pure species individuals that have been perfumed like hybrids. 


\section{DISCUSSION}

Prezygotic isolation is common in nature, but the high prevalence of gene flow suggest that prezygotic barriers are leaky (Irwin 2019). Hybridization is a common occurrence in all taxa in which surveys have been systematically performed (Harrison and Larson 2014b; Mallet et al. 2016; Taylor and Larson 2019). Over 10\% of animal species hybridize in nature, and the number might be higher for plants and fungi (Schardl and Craven 2003; Mallet 2005; Ellstrand 2014; Mallet et al. 2016). In cases where hybridization occurs, lower hybrid fitness is an important component of how

604 species persist in nature (Coughlan and Matute 2020). In this report, we describe that

605 Drosophila hybrids are less attractive to the pure species when the pure-species

606 individuals have a choice. This results indicate that even when hybrids are fertile, they

607 might suffer from subtle defects that reduced their fitness in nature and might limit their

608 ability to serve as genetic bridges for introgression. This defects might not be rare in

609 nature. Insect hybrids show anomalous courtship behavior (Noor 1997; Kost et al.

610 2016), while salmonid hybrids have trait combinations that make them less attractive to 611 pure species (Fukui et al. 2018).

612 In the case of the simulans and yakuba species complex, F1 hybrids have a $\mathrm{CHC}$

613 profile that is intermediate to that of their parents. Discrimination against hybrids seems

614 to be mediated by that intermediate profile. CHCs have been primarily implicated in two 615 important processes in insects: desiccation resistance, and communication (e.g., (Jallon 616 and David 1987; Foley and Telonis-Scott 2011; Arcaz et al. 2016) reviewed in (Gibbs 617 1998; Chung and Carroll 2015)). Drosophila hybrids often show intermediate blends of 618 CHCs (Coyne et al. 1994; Hercus and Hoffmann 1999; Gleason et al. 2009; Combs et 619 al. 2018) which poses the question of how generalizable our results are to other hybrids. 620 At least one case suggests the existence of a similar occurrence in beetles. Species of 621 the beetle genus Altica differ in their $\mathrm{CHC}$ profile. F1 hybrids between $A$. fragariae and

622 A. viridicyanea show $\mathrm{CHC}$ profiles that are intermediate from the parents but are also 623 distinct (Xue et al. 2018). Males from the pure species discriminate strongly against 624 hybrid females, potentially cued on their $\mathrm{CHC}$ blend profile (Xue et al. 2018). Only a 
625 broad-scale survey will reveal whether lower attractiveness is pervasive not only in Drosophila but across animals.

$\mathrm{CHCs}$ are regularly the target of natural and sexual selection (Menzel et al. 2017); species (Higgie et al. 2000) —and populations (Higgie and Blows 2008; Veltsos et al. 2012) — might differ as a result of local adaptation. There is no strong difference in desiccation resistance between $D$. simulans and $D$. mauritiana; differences between $D$. simulans lines are larger than the differences between species (Van Herrewege and David 1997). Drosophila santomea is slightly more resistant than D. yakuba to desiccation (Matute and Harris 2013), which might be explained not by its particular

$634 \mathrm{CHC}$ blend of the species but by its higher total $\mathrm{CHC}$ content in the cuticle (Mas and Jallon 2005). Even though D. simulans and D. yakuba are human commensals that tend to be found in dryer environments, the ecological effects behind the similarities and

637 differences in $\mathrm{CHC}$ profiles in these two species pairs remain unknown.

The two Drosophila species pairs studied here exchange alleles in nature. Drosophila yakuba and $D$. santomea form a hybrid zone in the midlands of São Tomé,

640 where $3-5 \%$ of the collected individuals (both males and females) from the yakuba clade 641 are hybrids (Comeault et al. 2016; Turissini and Matute 2017). To date, D. simulans and 642 D. mauritiana are not known to form an extant hybrid zone. In both cases, species 643 boundaries are porous and have allowed for introgression between species, but the 644 introgression between the two species is less than 1\% per genome per individual on average (Kliman et al. 2000; Bachtrog et al. 2006; Turissini and Matute 2017;

646 Meiklejohn et al. 2018). Hybrid males from the two species in this study are sterile, and 647 their fitness is effectively zero (Coyne 1985; Coyne et al. 2004). Hybrid male sterility is a 648 stronger form of isolation than the lower male sexual attractiveness reported here.

649 However, hybrid females from these species are fertile and can interbreed with males 650 from both pure species. The existence of hybrid defects that lead to selection against F1 651 hybrids might be important in the persistence of species that hybridize in nature.

653 that occur in nature. We cannot estimate the full extent of the fitness reduction that the 654 lower sexual attractiveness might cause. Field experiments of paternity and rates of insemination of hybrid females can reveal whether these defects also occur in nature. 
656 F1 hybrid stickleback males in natural enclosure experience strong sexual selection 657 against them as evidenced by the observation that limnetic males are more vigorous in 658 their display towards limnetic females - a proxy of mating success - than hybrid males 659 (Vamosi and Schluter 1999).

660 Comparative analyses have suggested that premating behavioral isolation is 661 completed relatively faster than hybrid sterility and inviability, and thus might play an 662 important role in setting the speciation process in motion (Coyne and Orr 1989, 1997; 663 Sasa et al. 1998; Moyle et al. 2004; Rabosky and Matute 2013; Castillo 2017).

664 Nonetheless, postzygotic isolation plays an important role in keeping species apart and 665 on completing prezygotic isolation via reinforcement (Rosenblum et al. 2012, Coughlan 666 and Matute 2020). Other forms of prezygotic isolation, not related to mating behavior, 667 also seem to evolve quickly (Turelli et al. 2014; Turissini et al. 2017). Future studies 668 should measure the rate of evolution of behavioral postzygotic isolation and assess 669 whether it is more akin to the rate of evolution of premating isolation or to that of hybrid 670 inviability and sterility. They should also compare the magnitude of the hybrid defect in 671 homo- and heterogametic sexes which would reveal whether Haldane's rule occurs in 672 behavioral postzygotic isolation.

673 Our focus on this study was to assess whether Drosophila hybrids suffer from 674 reduced attractiveness. Hybrid fitness is a continuum that ranges from hybrid vigor to 675 complete inviability (Guerrero et al. 2017; Dagilis et al. 2019). In some cases, hybrids 676 might be more attractive to their parentals that their own conspecifics (Pfennig 2007). 677 Hybrids might also be less attractive to the pure species but more attractive to other 678 hybrids thus facilitating hybrid speciation (e.g., (Mavárez et. al 2006; Melo et al. 2009; 679 Selz et al. 2014; Schmidt and Pfennig 2016; Comeault and Matute 2018). Only a 680 concerted effort to dissect the multiple fitness components of hybrids will reveal whether 681 discrimination against hybrids is widespread in nature and important for species 682 persistence, or on the contrary is an barrier to gene flow exclusively restricted to 683 Drosophila. 


\section{ACKNOWLEDGMENTS}

688

689 We would like to thank A.A. Comeault, B.S. Cooper and the members of the Matute lab for

690 helpful scientific discussions and comments. We would like to thank the Bioko Biodiversity

691 Protection Program (Equatorial Guinea), and the Ministry of Environment (Republic of São

692 Tomé and Príncipe) for permission to collect and export specimens for study. D.R.M. was

693 supported by the National Science Foundation (Award 1737752). The authors have no conflicts

694 of interest.

695

696

697 
FIGURES

700 FIGURE 1. Pure species males discriminate against heterospecific and hybrid

701 females in mate choice experiments. A-D. Proportion of males that chose a pure-

702 species conspecific female in mating experiments where they had the choice of mating

703 with conspecifics, heterospecfics, or F1 hybrid females. The black dot represents the

704 proportion of conspecific matings $(\mathrm{N}=300)$ and the bars show the $95 \%$ confidence

705 intervals calculated as Bayesian binomial intervals. A. D. yakuba males B. D. santomea

706 males C. D. simulans males D. D. mauritiana males. E-H. Female attractiveness

707 measurements in choice mating experiments. The proxy of female attractiveness is the

708 proportion of time that a male spends courting each type of female relative to the total

709 time that male spent courting all females. E. D. yakuba males F. D. santomea yakuba

710 males G. D. simulans males H. D. mauritiana males.

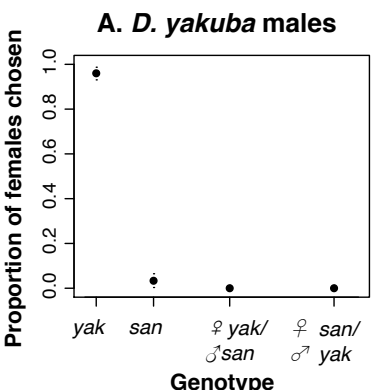

E. D. yakuba males

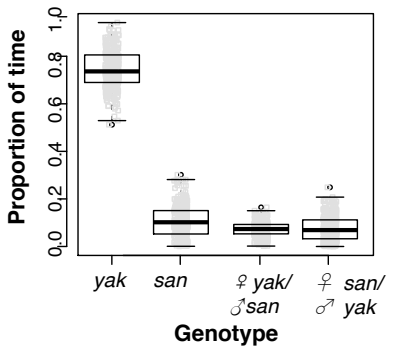

B. D. santomea males

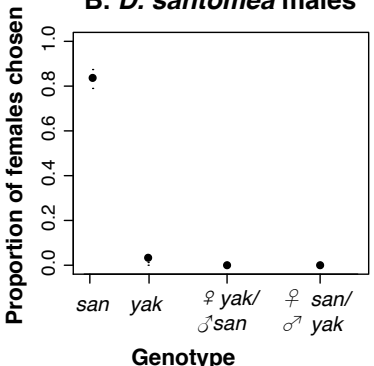

F. D. santomea males

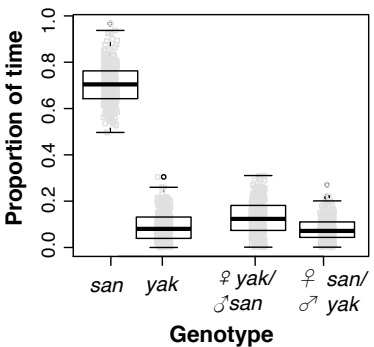

C. D. simulans males

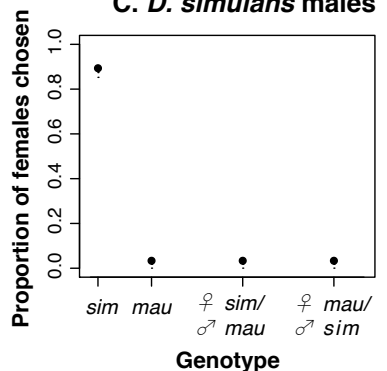

G. D. simulans males

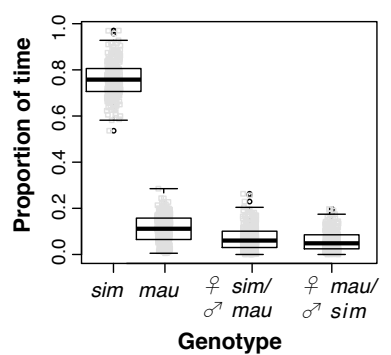

D. D. mauritiana males

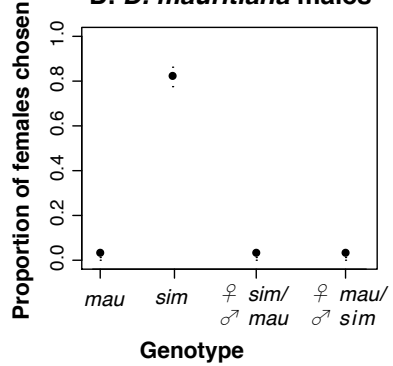

H. D. mauritiana males

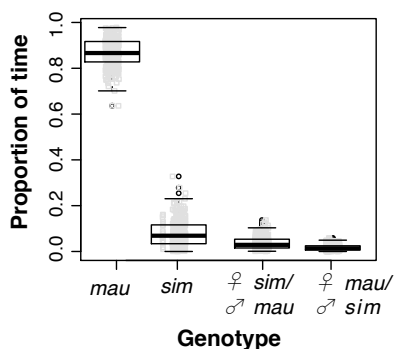


713 FIGURE 2. Pure species females engage in matings with heterospecific and

714 hybrid males more rarely than they do with conspecific males in no-choice

715 mating experiments. Proportion mated ( $y$-axis) indicates the proportion of matings that

716 led to a copulation $(\mathrm{N}=1,000)$. A. No-choice experiments with a $D$. yakuba female and

717 one of four types of males from different genotypes (D. yakuba, D. santomea, $\mathrm{F} 1$

718 q san/ồyak hybrid, F1 q yak/ôsan hybrid). B. No-choice experiments with a $D$.

719 santomea female and one of four types of males from different genotypes $(D$.

720 santomea, D. yakuba, F1 q san/ồyak hybrid, F1 qyak/ôsan hybrid). C. No-choice

721 experiments with a $D$. simulans female and one of four types of males from different

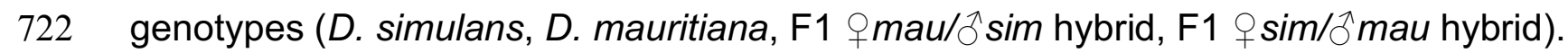

723 D. No-choice experiments with a $D$. mauritiana female and one of four types of males

724 from different genotypes (D. mauritiana, $D$. simulans, $\mathrm{F} 1+$ mau/ $§$ sim hybrid, $\mathrm{F} 1$

725 s sim/ $\$$ mau hybrid). Pairwise comparisons are shown in Table S9.

A. D. yakuba

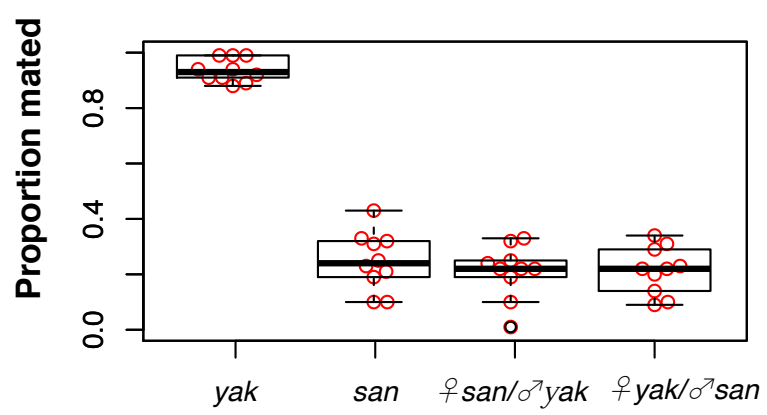

Genotype

C. D. simulans

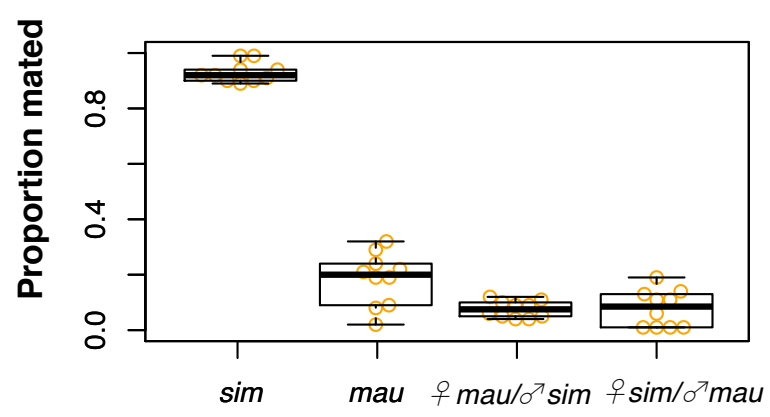

Genotype
B. D. santomea

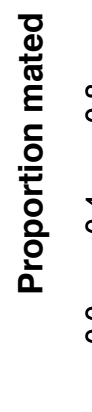

\section{.}

.

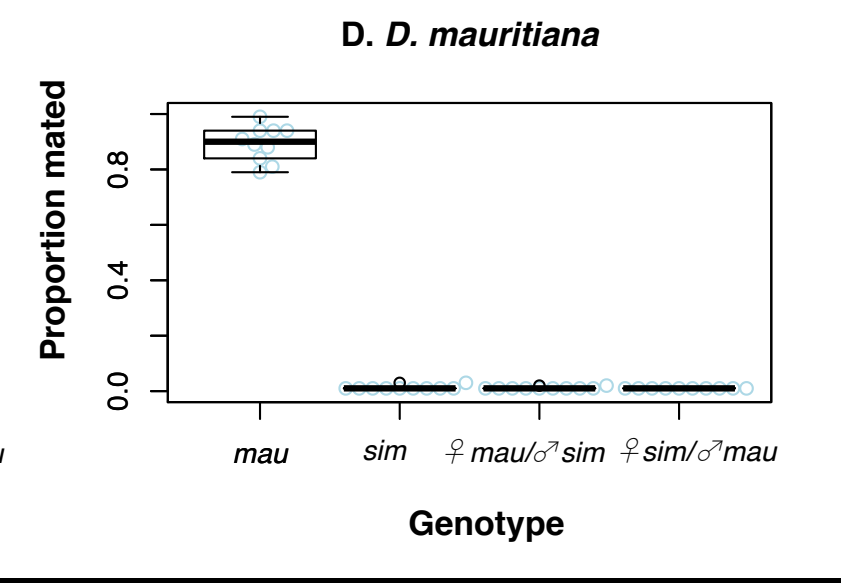


728 FIGURE 3. Males put more effort in matings with conspecific matings than in matings

729 with heterospecific and hybrid females in non-choice experiments. The proxy of effort is

730 the number of time windows (scored every 2 mins) in which the males were courting the

731 female divided by the mating latency. A. No-choice experiments with a $D$. yakuba

732 female and one of four types of males from different genotypes $(D$. yakuba, $D$.

733 santomea, F1 q san/ồ yak hybrid, F1 q yak/ôsan hybrid). B. No-choice experiments with

734 a $D$. santomea female and one of four types of males from different genotypes $(D$.

735 santomea, D. yakuba, F1 q san/ôyak hybrid, F1 qyak/ôsan hybrid). C. No-choice

736 experiments with a $D$. simulans female and one of four types of males from different

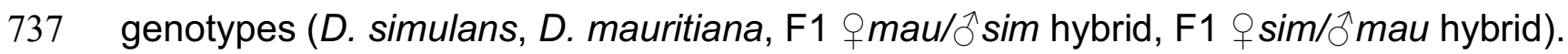

738 D. No-choice experiments with a $D$. mauritiana female and one of four types of males

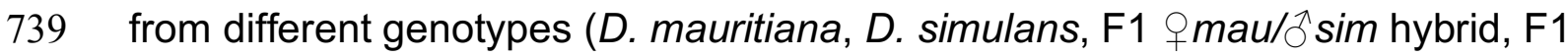

$740 \quad$ s sim/ $\$$ mau hybrid). Pairwise comparisons are shown in Table S10.

A. D. yakuba

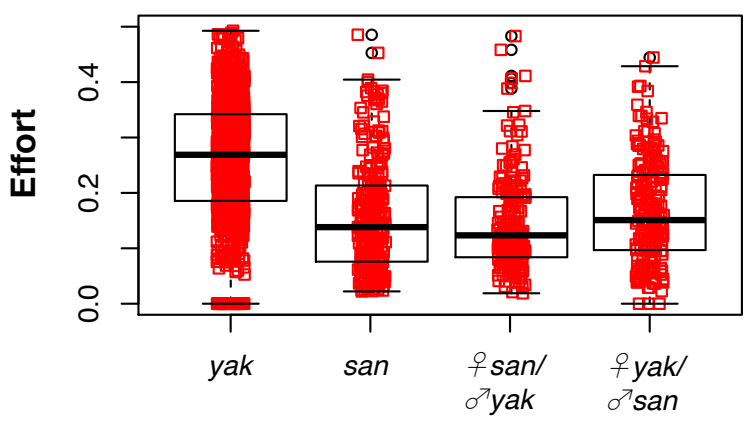

Genotype

C. D. simulans

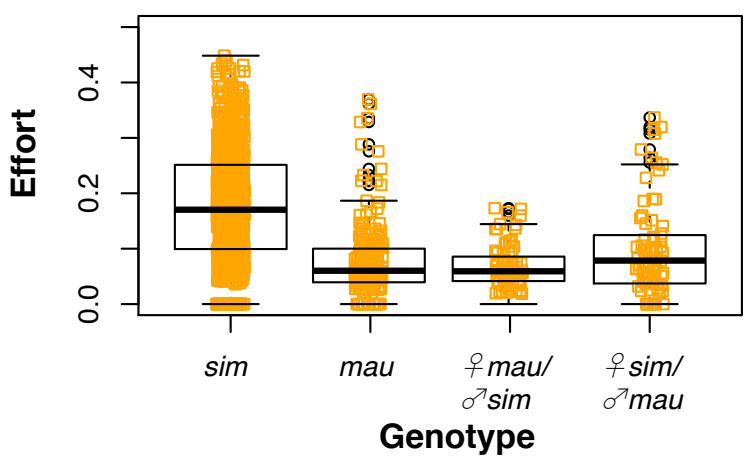

B. D. santomea

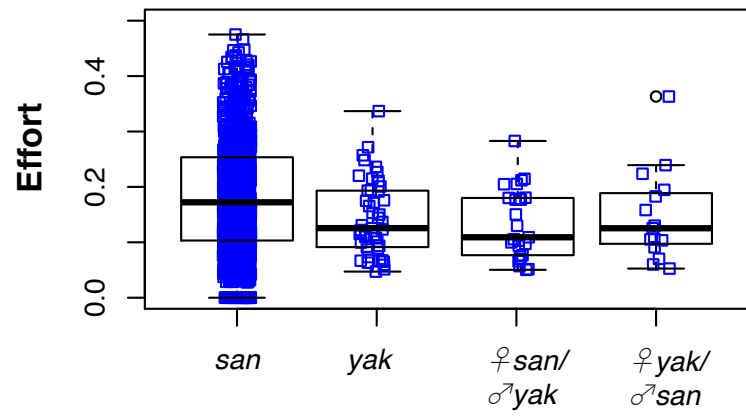

Genotype

D. D. mauritiana

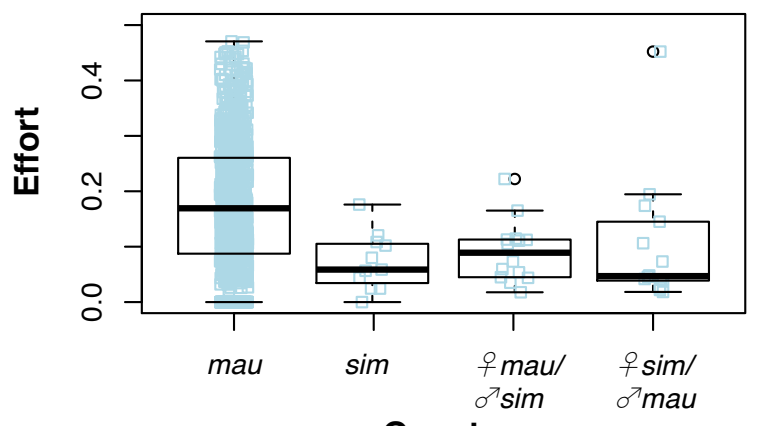

Genotype 
744 hybrid females. Ellipses indicate a multinomial distribution of the data, variance explained by each PC is given in 745 parentheses. PCA is based on the quantity of four CHCs for $D$. yakuba and $D$. santomea and six for $D$. simulans and $D$.

746 mauritiana (see methods). A. D. yakuba, D. santomea, and reciprocal F1 hybrids B. D. simulans, D. mauritiana, and F1 747 q sim/ふ̄mau hybrids.

748

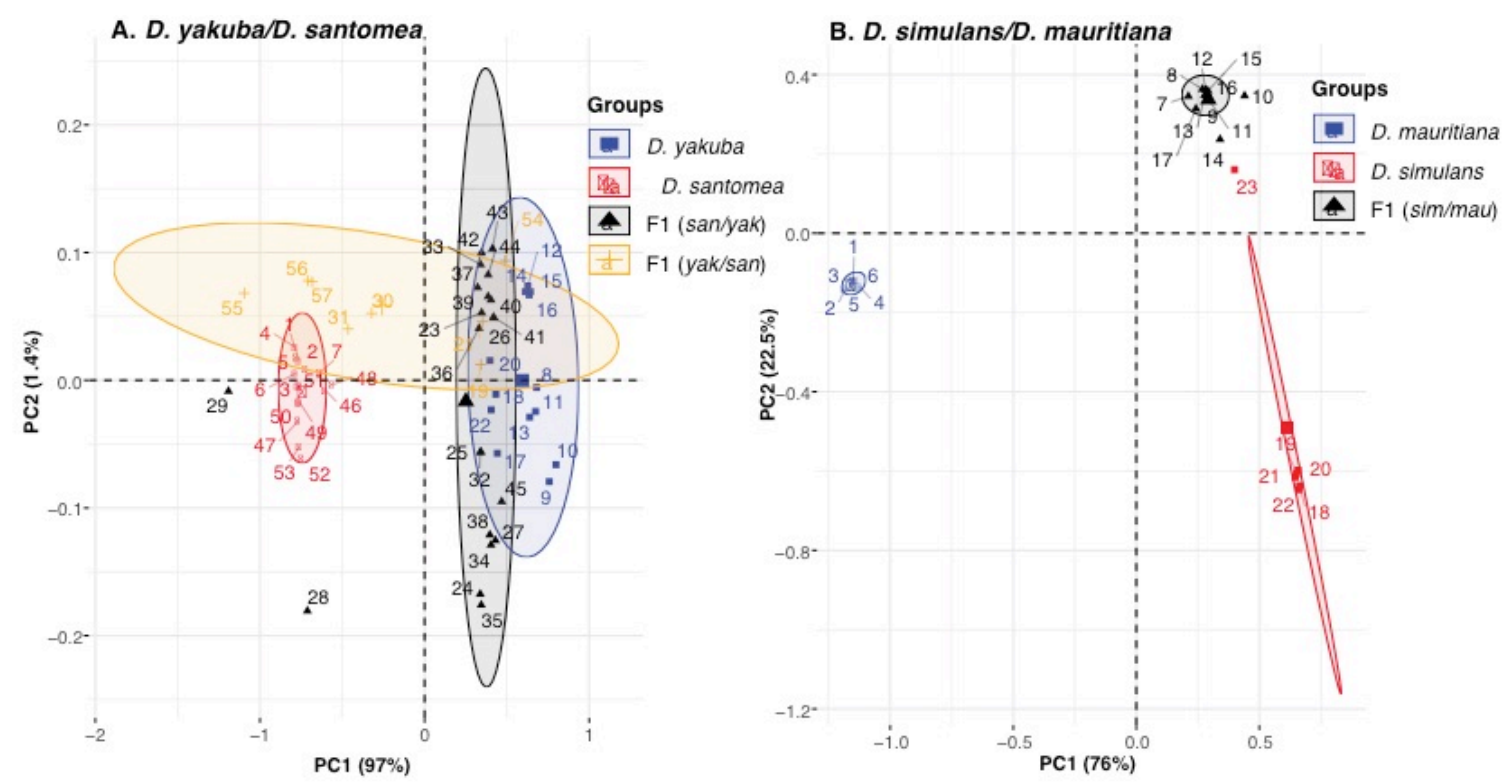


751 profile. The perfuming treatment consisted of raising a single fly with a group of 10 flies from a different genotype. For this 752 section, we focused on the study of $D$. simulans $(A), D$. mauritiana $(B)$ and $F 1(q \operatorname{sim} / \delta$ mau) hybrids $(C)$. Pure species and $753 \mathrm{~F} 1$ ( sim/mau) hybrids are shown using the same colors as in Figure 3. (Please note these data is the same as Figure 3 ). 754 Perfumed samples are shown in one of two shades of gray.) In the legend, the genotype of the fly appears first, and the 755 perfuming treatment (i.e., the genotype of individuals placed along the focal fly) appears second (species/perfume).
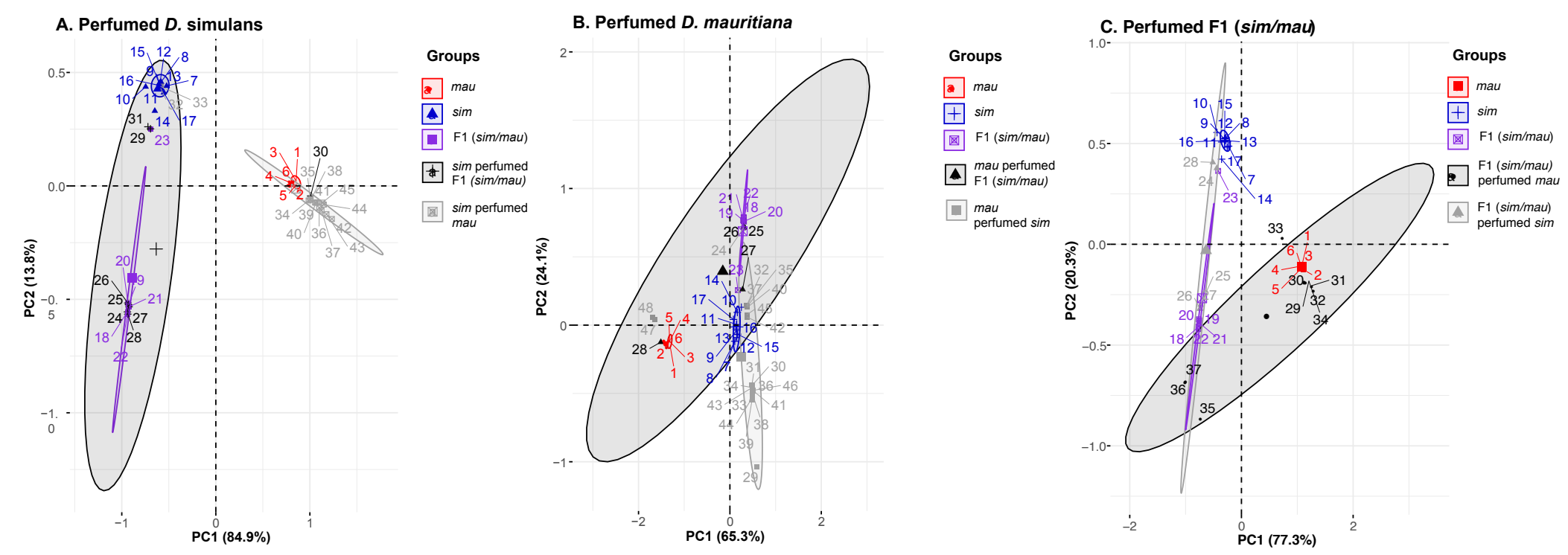
FIGURE 6. Perfuming hybrid females with the $\mathrm{CHC}$ blend of pure species changes their attractiveness to pure species males. Each experiment consisted of a pure species male having the choice of three different females with identical genotypes but differences in their perfuming treatment. Each point shows the proportion of the three types of females chosen in a block of matings ( $n=50$ observations). The red line shows the expected mating frequencies for the three types of females if perfuming has no effect on sexual attractiveness. Pairwise comparisons between perfuming categories are shown in Table S17. Treatments that significantly differ from the 1/3 expectation are

A. D. yakuba

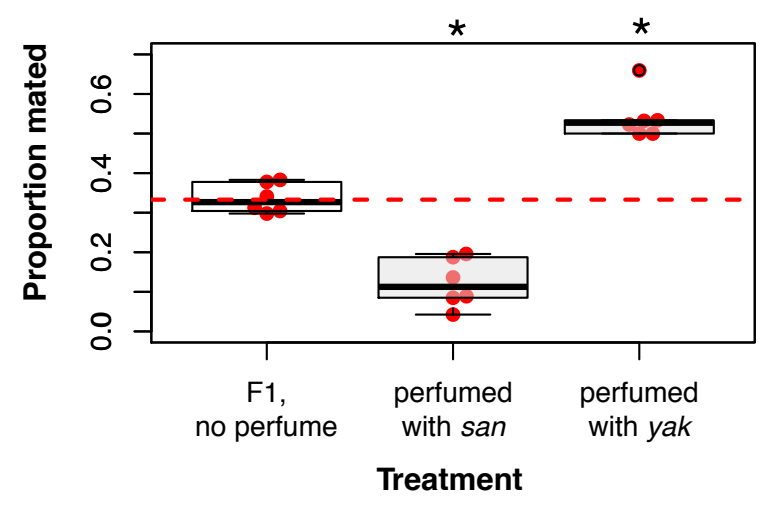

C. D. simulans

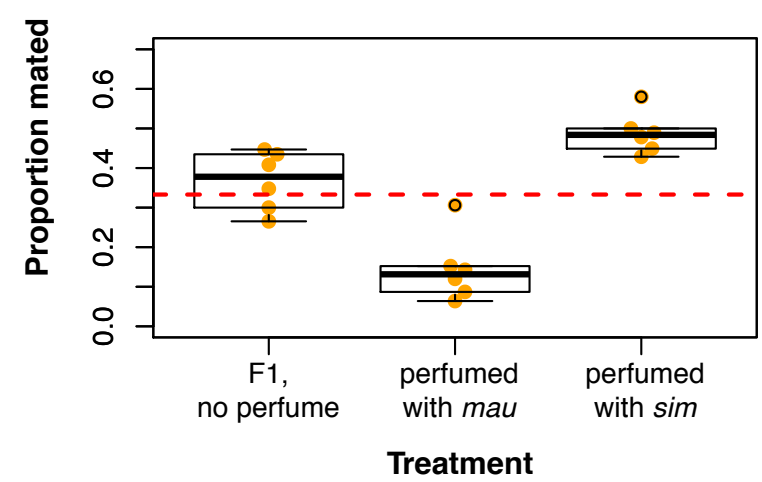

B. D. santomea

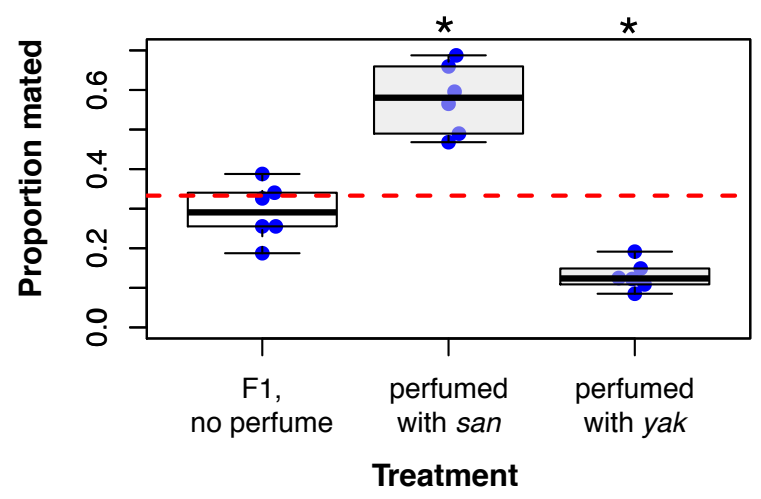

D. D. mauritiana

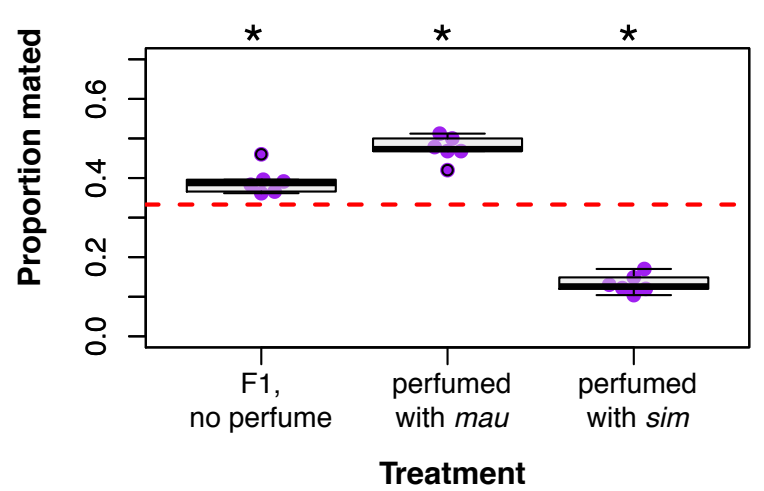


772 FIGURE 7. Perfuming pure species females with the CHC blend of heterospecifics

773 or hybrid females reduces their attractiveness to pure species males. Each

774 experiment consisted of a pure species male having the choice of three conspecific

775 females with identical genotypes but differences in their $\mathrm{CHC}$ blend. Each point shows

776 the proportion of the three types of females chosen in a block of matings ( $n=50$

777 observations). The red line shows the expected mating frequencies for the three types

778 of females if perfuming has no effect on attractiveness. Pairwise comparisons between

779 perfuming categories are shown in Table S18. None of the three treatments significantly

780 differs from the $1 / 3$ expectation.

\section{A. D. yakuba}

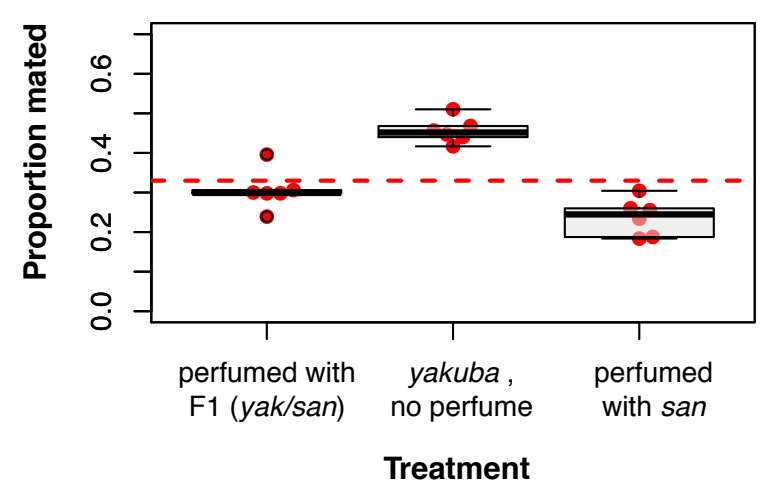

C. D. simulans

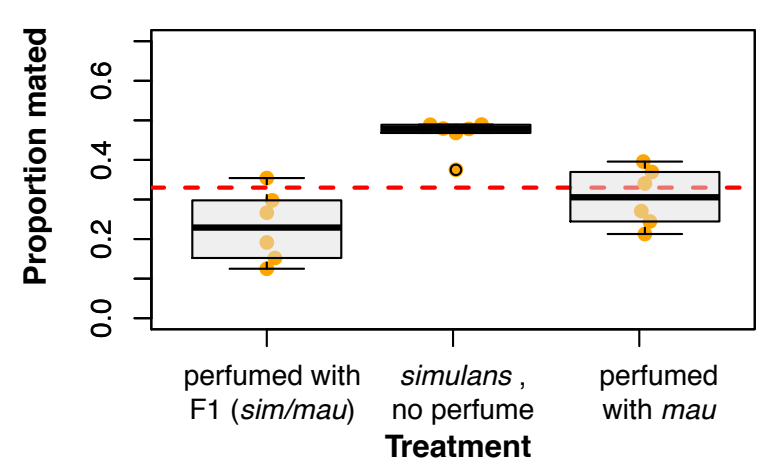

B. D. santomea

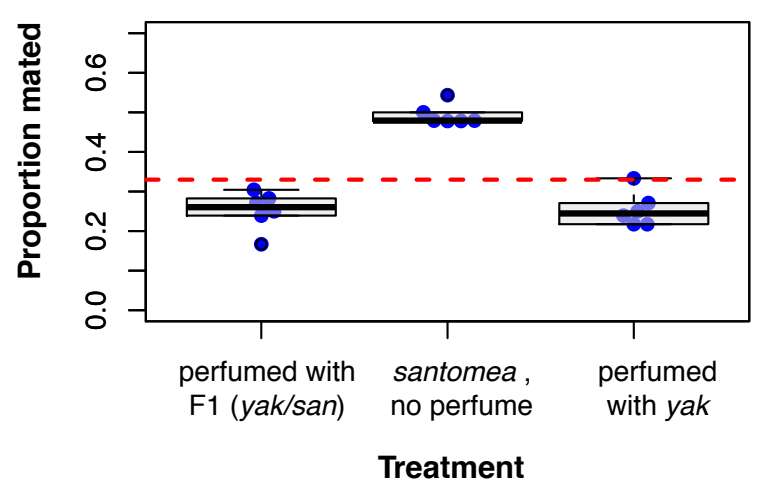

D. D. mauritiana

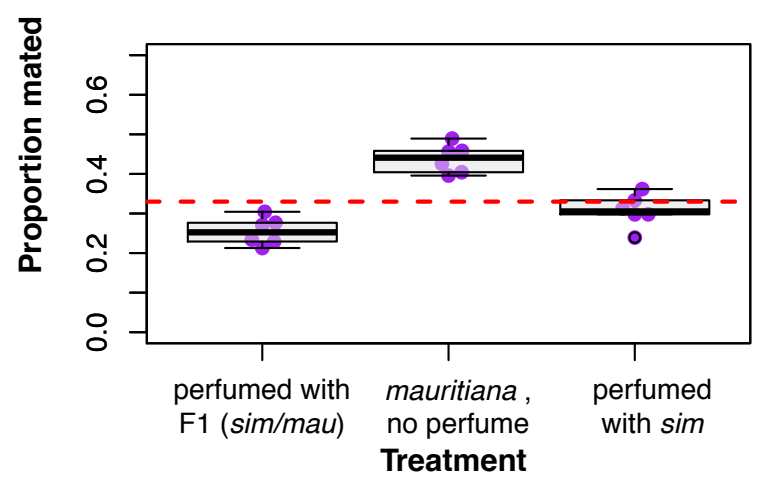




\section{TABLES}

786 TABLE 1. Copulation latency in matings with conspecific, heterospecific, and

787 hybrid males in no-choice experiments. Matings with heterospecific and hybrid males

788 take longer to occur than conspecific matings. $N$ represents the number of mated pairs

789 (out of 1,000 attempts) used for the analyses. All the means (percentage of females

790 mated) and standard deviations (SD). The last four columns show pairwise comparisons

791 as $4 \times 4$ matrices for each cross. The lower triangular matrix shows the t value from a

792 multiple comparisons of means using Tukey contrasts. The upper triangular matrix

793 shows the P-value associated to the comparison. All p-values were adjusted for

794 multiple comparisons.

\begin{tabular}{|c|c|c|c|c|c|c|}
\hline \multicolumn{7}{|c|}{ D. yakuba females } \\
\hline \multirow{2}{*}{$\begin{array}{l}\text { Male } \\
\text { genotype }\end{array}$} & \multirow[t]{2}{*}{$\mathrm{N}$} & \multirow{2}{*}{$\begin{array}{l}\text { Mean } \\
(\mathrm{SD}) / \mathrm{min}\end{array}$} & \multicolumn{4}{|c|}{ Pairwise comparisons } \\
\hline & & & D. yakuba & D. santomea & $\begin{array}{l}\text { F1 (q } \\
\text { yak x } \\
\text { osan) }\end{array}$ & $\begin{array}{l}\text { F1 (q } \\
\operatorname{san} \times \\
\text { đyak) }\end{array}$ \\
\hline D. yakuba & 939 & $\begin{array}{l}11.300( \\
4.594)\end{array}$ & * & $<0.001$ & $<0.001$ & $<0.001$ \\
\hline $\begin{array}{l}D . \\
\text { santomea }\end{array}$ & 247 & $\begin{array}{l}31.293( \\
10.865)\end{array}$ & 33.361 & * & $<0.001$ & 0.912 \\
\hline $\begin{array}{l}\text { F1 (q yak x } \\
\text { ôsan) }\end{array}$ & 214 & $\begin{array}{l}27.864 \\
(12.820)\end{array}$ & 26.091 & 4.382 & * & 0.002 \\
\hline $\begin{array}{l}\mathrm{F} 1(\text { q } \operatorname{san} x \\
\text { †yak) }\end{array}$ & 210 & $\begin{array}{l}30.780 \\
(11.771)\end{array}$ & 30.450 & 0.652 & 3.583 & * \\
\hline \multicolumn{7}{|c|}{ D. santomea females } \\
\hline \multirow{2}{*}{$\begin{array}{l}\text { Male } \\
\text { genotype }\end{array}$} & \multirow[t]{2}{*}{$\mathrm{N}$} & \multirow{2}{*}{$\begin{array}{l}\text { Mean } \\
(\mathrm{SD}) / \mathrm{min}\end{array}$} & \multicolumn{4}{|c|}{ Pairwise comparisons } \\
\hline & & & $\begin{array}{l}D . \\
\text { santomea }\end{array}$ & D. yakuba & $\begin{array}{l}\text { F1 (q } \\
\text { yak x } \\
\text { ¡san) }\end{array}$ & $\begin{array}{l}\text { F1 (q } \\
\text { san x } \\
\text { §yak) }\end{array}$ \\
\hline $\begin{array}{l}D . \\
\text { santomea }\end{array}$ & 928 & $\begin{array}{l}24.480 \\
(10.450)\end{array}$ & * & $<0.001$ & 0.006 & $<0.001$ \\
\hline
\end{tabular}




\begin{tabular}{|c|c|c|c|c|c|c|}
\hline D. yakuba & 45 & $\begin{array}{l}40.694 \\
(7.993)\end{array}$ & 10.311 & * & 0.062 & 0.557 \\
\hline $\begin{array}{l}\text { F1 (+ yak x } \\
\text { ôsan) }\end{array}$ & 15 & $\begin{array}{l}33.161 \\
(10.311)\end{array}$ & 3.238 & 2.452 & * & 0.559 \\
\hline $\begin{array}{l}\mathrm{F} 1(+\operatorname{san} \times \\
\text { ôyak) }\end{array}$ & 25 & $\begin{array}{l}37.429 \\
(8.037)\end{array}$ & 6.202 & 1.271 & 1.268 & * \\
\hline
\end{tabular}

\begin{tabular}{|c|c|c|c|c|c|c|}
\hline \multirow{2}{*}{$\begin{array}{l}\text { Male } \\
\text { genotype }\end{array}$} & \multirow[t]{2}{*}{$\mathrm{N}$} & \multirow{2}{*}{$\begin{array}{l}\text { Mean } \\
(\mathrm{SD}) / \mathrm{min}\end{array}$} & \multicolumn{4}{|c|}{ Pairwise comparisons } \\
\hline & & & $\begin{array}{l}D . \\
\text { simulans }\end{array}$ & D. mauritiana & $\begin{array}{l}\text { F1 (P } \\
\text { sim } \times \\
\text { Ômau) }\end{array}$ & $\begin{array}{l}\mathrm{F} 1(+ \\
\text { mau } \times \\
\text { ôsim) }\end{array}$ \\
\hline D. simulans & 931 & $\begin{array}{l}14.173 \\
(5.829)\end{array}$ & * & $<0.001$ & $<0.001$ & $<0.001$ \\
\hline $\begin{array}{l}D . \\
\text { mauritiana }\end{array}$ & 185 & $\begin{array}{l}30.857 \\
(12.961)\end{array}$ & 32.634 & * & 0.055 & $<0.001$ \\
\hline $\begin{array}{l}\mathrm{F} 1(+\operatorname{sim} \times \\
\text { Òmau) }\end{array}$ & 75 & $\begin{array}{l}33.358 \\
(10.168)\end{array}$ & 19.032 & 2.502 & * & $<0.001$ \\
\hline $\begin{array}{l}\mathrm{F} 1(+\mathrm{mau} \\
\times \widehat{\jmath} \operatorname{sim})\end{array}$ & 75 & $\begin{array}{l}40.460 \\
(7.587)\end{array}$ & 29.986 & 7.102 & 8.052 & * \\
\hline
\end{tabular}

\begin{tabular}{|c|c|c|c|c|c|c|}
\hline \multirow{2}{*}{$\begin{array}{l}\text { Male } \\
\text { genotype }\end{array}$} & \multirow[t]{2}{*}{$\mathrm{N}$} & \multirow{2}{*}{$\begin{array}{l}\text { Mean } \\
\text { (SD) /min }\end{array}$} & \multicolumn{4}{|c|}{ Pairwise comparisons } \\
\hline & & & $\begin{array}{l}\text {. } \\
\text { mauritiana }\end{array}$ & D. simulans & $\begin{array}{l}\text { F1 (q } \\
\operatorname{sim} \times \\
\text { ômau) }\end{array}$ & $\begin{array}{l}\mathrm{F} 1(+9 \\
\text { mau } \times \\
\text { ôsim) }\end{array}$ \\
\hline $\begin{array}{l}D . \\
\text { mauritiana }\end{array}$ & 894 & $\begin{array}{l}21.038 \\
(10.117)\end{array}$ & * & $<0.001$ & $<0.001$ & $<0.001$ \\
\hline D. simulans & 11 & $\begin{array}{l}40.087 \\
(6.053)\end{array}$ & 6.179 & * & 0.997 & 0.952 \\
\hline $\begin{array}{l}\text { F1 (q } \operatorname{sim} \times \\
\text { Ômau) }\end{array}$ & 14 & $\begin{array}{l}39.249 \\
(14.291)\end{array}$ & 6.653 & 0.205 & * & 0.860 \\
\hline
\end{tabular}




\begin{tabular}{|c|c|c|c|c|c|c|}
\hline $\begin{array}{l}\mathrm{F} 1 \text { ( }+\mathrm{mau} \\
\times \text { ○̂sim) }\end{array}$ & 14 & $\begin{array}{l}42.182 \\
(10.798)\end{array}$ & 7.725 & 0.512 & 0.764 & * \\
\hline
\end{tabular}

TABLE 2. Pure species and F1 hybrids tend to show differences in their joint CHC profile in the two studies species pairs. We performed pairwise comparisons using a

799 Tukey test following a One-way ANOVA. The lower triangular matrix shows the $t$ value

800 from a multiple comparisons of means using Tukey contrasts. The upper triangular

801 matrix shows the P-value associated to the comparison. Please note that we limited our

802 analyses to PC1, because that PC explains over $75 \%$ of the variance in both species

803 pairs. Figure 4 shows a representation of the same results.

D. yakuba/ D. santomea: $\mathrm{F}_{3,53}=42.185, \mathrm{P}<1 \times 10^{-10}$

\section{Pairwise comparisons}

\begin{tabular}{|c|c|c|c|c|}
\hline $\begin{array}{l}\text { Genotype } \\
\text { 1/Genotype } 2\end{array}$ & D. yakuba & D. santomea & $\begin{array}{l}\text { F1 (q yak x } \\
\text { osan) }\end{array}$ & $\begin{array}{l}\text { F1 ( } \uparrow \operatorname{san} x \\
\uparrow \text { yak) }\end{array}$ \\
\hline D. yakuba & * & $<0.001$ & $<0.001$ & 0.0269 \\
\hline D. santomea & 10.345 & * & 0.0129 & $<0.001$ \\
\hline F1 ( $\uparrow$ yak x $\bigcirc$ san) & 5.645 & 3.160 & * & 0.003 \\
\hline F1 ( $\uparrow$ san $\times \bigcirc^{\lambda}$ yak) & 2.892 & 8.576 & 3.648 & * \\
\hline
\end{tabular}

\section{Pairwise comparisons}

\begin{tabular}{|c|c|c|c|c|}
\hline $\begin{array}{l}\text { Genotype } \\
\text { 1/Genotype } 2\end{array}$ & D. simulans & $\begin{array}{l}D . \\
\text { mauritiana }\end{array}$ & 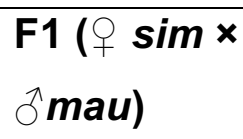 & $\begin{array}{l}\text { F1 ( } \bigcirc \text { mau } \times \\
\curlywedge \text { sim) }\end{array}$ \\
\hline D. simulans & * & $<0.001$ & $<0.001$ & NA \\
\hline D. mauritiana & 42.18 & * & $<0.001$ & NA \\
\hline F1 ( $\left.+\operatorname{sim} \times{ }^{\lambda} \mathbf{m a u}\right)$ & 9.35 & 45.30 & * & NA \\
\hline F1 ( $q$ mau $\times$ sim) & NA & $\mathrm{NA}$ & NA & * \\
\hline
\end{tabular}

TABLE 3. Perfuming experiments induce differences in the joint CHC profile in $D$.

807 simulans, $D$. mauritiana and F1 hybrids. We focus on the species of the $D$.

808 simulans species group (D. simulans and D. mauritiana). We performed pairwise 
809 comparisons using a Tukey test following a One-way ANOVA. The lower triangular

810 matrix shows the $t$ value from multiple comparisons of means using Tukey contrasts.

811 The upper triangular matrix shows the P-value associated to the comparison. All P-

812 values were adjusted for multiple comparisons. Please note that we limited our

813 analyses to PC1, because that PC explains over $75 \%$ of the variance in both species

814 pairs. Figure 4 shows a representation of the same results.

\begin{tabular}{|c|c|c|c|c|c|}
\hline \multicolumn{5}{|c|}{ D. simulans perfuming experiments: $F_{4,40}=32.695, P<1 \times 10^{-10}$} & \\
\hline \multirow[b]{2}{*}{$\begin{array}{l}\text { Genotype } \\
\text { 1/Genotype } \\
2\end{array}$} & \multicolumn{5}{|c|}{ Pairwise comparisons } \\
\hline & $\begin{array}{l}D . \\
\text { simulans }\end{array}$ & $\begin{array}{l}\text { F1 ( }+\operatorname{sim} x \\
\text { Ómau) }\end{array}$ & $\begin{array}{l}\text { D. } \\
\text { simulans } \\
\text { perfumed } \\
\text { with F1 ( } 9 \\
\text { sim } \times \\
\text { İmau) }\end{array}$ & $\begin{array}{l}\text { D. simulans } \\
\text { perfumed } \\
\text { with mau }\end{array}$ & $\begin{array}{l}\text { D. } \\
\text { mauritiana }\end{array}$ \\
\hline $\begin{array}{l}\text { D. } \\
\text { simulans }\end{array}$ & * & 0.709 & 1.000 & $<0.001$ & $<0.001$ \\
\hline $\begin{array}{l}\mathbf{F 1}(\uparrow \operatorname{sim} \times \\
\left.\oint^{\lambda} \mathbf{m a u}\right)\end{array}$ & 1.267 & * & 0.821 & $<0.001$ & $<0.001$ \\
\hline $\begin{array}{l}D . \\
\text { simulans } \\
\text { perfumed } \\
\text { with F1 ( }+ \\
\text { sim x } \\
\text { Tmau) }\end{array}$ & 0.147 & 1.064 & * & $<0.001$ & $<0.001$ \\
\hline $\begin{array}{l}\text { D. } \\
\text { simulans } \\
\text { perfumed } \\
\text { with mau }\end{array}$ & 8.020 & 7.941 & 7.445 & * & 1.000 \\
\hline $\begin{array}{l}\text { D. } \\
\text { mauritiana }\end{array}$ & 6.368 & 6.712 & 6.111 & 0.001 & * \\
\hline D. mauritian & erf & erimen & $3=12.5$ & $=7.305$ & \\
\hline
\end{tabular}




\begin{tabular}{|c|c|c|c|c|c|}
\hline & Pairwise co & mparisons & & & \\
\hline $\begin{array}{l}\text { Genotype } \\
\text { 1/Genotype } \\
2\end{array}$ & $\begin{array}{l}D . \\
\text { mauritiana }\end{array}$ & $\begin{array}{l}\text { F1 ( }+\operatorname{sim} \times \\
\partial^{\lambda} \text { mau) }\end{array}$ & $\begin{array}{l}\text { D. } \\
\text { mauritiana } \\
\text { perfumed } \\
\text { with F1 ( }+ \\
\text { sim } \times \\
\text { Thau) }\end{array}$ & $\begin{array}{l}D . \\
\text { mauritiana } \\
\text { perfumed } \\
\text { with sim }\end{array}$ & D. simulans \\
\hline $\begin{array}{l}D . \\
\text { mauritiana }\end{array}$ & * & $<0.001$ & 0.007 & $<0.001$ & $<0.001$ \\
\hline $\begin{array}{l}\text { F1 }(q \operatorname{sim} x \\
\text { mau) }\end{array}$ & 5.548 & * & 0.651 & 0.999 & 0.985 \\
\hline $\begin{array}{l}D . \\
\text { mauritiana } \\
\text { perfumed } \\
\text { with F1 ( } ९ \\
\text { sim } \times \\
\text { đlmau) }\end{array}$ & 3.611 & 1.352 & * & 0.570 & 0.824 \\
\hline $\begin{array}{l}\text { D. } \\
\text { mauritiana } \\
\text { perfumed } \\
\text { with sim }\end{array}$ & 6.780 & 1.721 & 1.481 & * & 0.984 \\
\hline $\begin{array}{l}D . \\
\text { simulans }\end{array}$ & 5.800 & 6.015 & 1.050 & 0.523 & * \\
\hline \multicolumn{6}{|c|}{ F1 perfuming experiments: $F_{4,32}=13.472, P=1.522 \times 10^{-6}$} \\
\hline & \multicolumn{5}{|c|}{ Pairwise comparisons } \\
\hline $\begin{array}{l}\text { Genotype } \\
\text { 1/Genotype } \\
2\end{array}$ & F1 & D. simulans & $\begin{array}{l}\text { D. } \\
\text { mauritiana }\end{array}$ & $\begin{array}{l}\text { F1 ( }+ \text { sim } x \\
\text { fmau) } \\
\text { perfumed } \\
\text { with sim }\end{array}$ & $\begin{array}{l}\text { F1 ( }+ \text { sim x } \\
\text { perfumed } \\
\text { with mau }\end{array}$ \\
\hline $\begin{array}{l}\text { F1 ( } q \operatorname{sim} \text { x } \\
\text { 'mau) }\end{array}$ & * & 0.567 & $<0.001$ & 0.999 & 0.002 \\
\hline
\end{tabular}


bioRxiv preprint doi: https://doi.org/10.1101/2020.07.22.214924; this version posted July 23, 2020. The copyright holder for this preprint (which was not certified by peer review) is the author/funder, who has granted bioRxiv a license to display the preprint in perpetuity. It is made available under aCC-BY 4.0 International license.

\begin{tabular}{|l|l|l|l|l|l|}
\hline $\begin{array}{l}\text { D. } \\
\text { simulans }\end{array}$ & 1.500 & $*$ & $<0.001$ & 0.768 & 0.020 \\
\hline $\begin{array}{l}\text { D. } \\
\text { mauritiana }\end{array}$ & 5.861 & 5.168 & $*$ & $<0.001$ & 0.205 \\
\hline $\begin{array}{l}\text { F1 ( } 9 \text { sim } \times \\
\text { Omau) } \\
\text { perfumed } \\
\text { with sim }\end{array}$ & 0.219 & 1.165 & 5.369 & $*$ & 0.0056 \\
\hline $\begin{array}{l}\text { F1 ( }+ \text { sim } \times \\
\text { Tmau) } \\
\text { perfumed } \\
\text { with mau }\end{array}$ & 4.225 & 3.260 & 2.196 & 3.754 & $*$ \\
\hline
\end{tabular}




\section{REFERENCES}

Arcaz, A. C., D. L. Huestis, A. Dao, A. S. Yaro, M. Diallo, J. Andersen, G. J. Blomquist, and T. Lehmann. 2016. Desiccation tolerance in Anopheles coluzzii: The effects of spiracle size and cuticular hydrocarbons. J. Exp. Biol., 219: 1675-1688. doi: 10.1242/jeb.135665.

Bachtrog, D., K. Thornton, A. Clark, and P. Andolfatto. 2006. Extensive introgression of mitochondrial DNA relative to nuclear genes in the Drosophila yakuba species group. Evolution. 60:292-302.

Bates D, Mächler M, Bolker B, Walker S (2015). Fitting Linear Mixed-Effects Models Using Ime4. Journal of Statistical Software, 67(1), 1-48. doi: 10.18637/jss.v067.i01.

Blomquist, G. J., and A. G. Bagnères. 2010. Insect hydrocarbons biology, biochemistry, and chemical ecology. Cambridge University Press.

Brand, C. L., S. B. Kingan, L. Wu, and D. Garrigan. 2013. A selective sweep across species boundaries in Drosophila. Mol. Biol. Evol., 30: 2177-2186. doi: 10.1093/molbev/mst123.

Cady, A. B., K. J. Delaney, and G. W. Uetz. 2011. Contrasting energetic costs of courtship signaling in two wolf spiders having divergent courtship behaviors. J. Arachnol., 39: 161-165. doi: 10.1636/hi09-70.1.

Campbell, D. R. 2004. Natural selection in Ipomopsis hybrid zones: Implications for ecological speciation. 161: 83-90.

Campbell, D. R., N. M. Waser, and E. J. Meléndez-Ackerman. 1997. Analyzing

Castillo, D. M. 2017. Factors contributing to the accumulation of reproductive isolation: A mixed model approach. Ecol. Evol., 7: 5808-5820. doi: 10.1002/ece3.3093.

Chung, H., and S. B. Carroll. 2015. Wax, sex and the origin of species: Dual roles of insect cuticular hydrocarbons in adaptation and mating. BioEssays 37:822-830. 
847 Combs, P.A., Krupp, J.J., Khosla, N.M., Bua, D., Petrov, D.A., Levine, J.D. and Fraser, H.B., 2018. Tissue-specific cis-regulatory divergence implicates eloF in inhibiting interspecies mating in Drosophila. Curr Biol, 28: 3969-3975.

Comeault, A. A., and D. R. Matute. 2018. Genetic divergence and the number of hybridizing species affect the path to homoploid hybrid speciation. Proc. Natl. Acad. Sci., 115: 9761-9766. doi: 10.1073/pnas.1809685115.

Comeault, A. A., A. Venkat, and D. R. Matute. 2016. Correlated evolution of male and female reproductive traits drive a cascading effect of reinforcement in Drosophila yakuba. Proc. R. Soc. London B Biol. Sci. 283:20160730.

Cooper, B. S., A. Sedghifar, W. T. Nash, A. A. Comeault, and D. R. Matute. 2018. A maladaptive combination of traits contributes to the maintenance of a Drosophila hybrid zone. Curr. Biol., 28: 2940-2947. doi: 10.1016/j.cub.2018.07.005.

Coyne, J. A. 1985. Genetic studies of three sibling species of Drosophila with relationship to theories of speciation. Genet. Res., 46: 169-192. doi:

Coyne, J. A., S. Elwyn, S. Y. Kim, and A. Llopart. 2004. Genetic studies of two sister species in the Drosophila melanogaster subgroup, D. yakuba and D. santomea. Genet. Res. 84: 11-26

Coyne, J. A., and H. A. Orr. 1989. Patterns of Speciation in Drosophila. Evolution. 43:362-381.

Coyne, J. A., and H. A. Orr. 1997. "Patterns of Speciation in Drosophila" Revisited. Evolution. 51:295-303.

874 Dagilis, A. J., M. Kirkpatrick, and D. I. Bolnick. 2019. The evolution of hybrid fitness 875 during speciation. PLoS Genet., 15: e1008125. doi: 10.1371/journal.pgen.1008125. 876 Delmore, K. E., and D. E. Irwin. 2014. Hybrid songbirds employ intermediate routes in a migratory divide. Ecol. Lett. 17:1211-1218. 
878

Dembeck, L. M., K. Böröczky, W. Huang, C. Schal, R. R. H. Anholt, and T. F. C. Mackay. 2015. Genetic architecture of natural variation in cuticular hydrocarbon composition in Drosophila melanogaster. Elife 4, p.e09861.

Denis, B., A. Le Rouzic, and C. Wicker-Thomas. 2015. Hydrocarbon patterns and mating behaviour in populations of Drosophila yakuba. Insects, 6: 897-911. doi: 10.3390/insects6040897.

Dobzhansky, T. 1937. Genetics and the Origin of Species. Columbia University Press.

Ejima, A., and L. C. Griffith. 2007. Measurement of courtship behavior in Drosophila melanogaster . Cold Spring Harb. Protoc., 10:pdb-rot4847. doi: 10.1101/pdb.prot4847.

Ellstrand, N. C. 2014. Is gene flow the most important evolutionary force in plants? Am. J. Bot. 101:737-753.

Ferveur, J. F. 2005. Cuticular hydrocarbons: Their evolution and roles in Drosophila pheromonal communication. Behav. Genet., 35: 279.

Ferveur, J. F., and M. Cobb. 2010. Behavioral and evolutionary roles of cuticular hydrocarbons in diptera. P. in Insect Hydrocarbons Biology, Biochemistry, and Chemical Ecology.

Foley, B. R., and M. Telonis-Scott. 2011. Quantitative genetic analysis suggests causal association between cuticular hydrocarbon composition and desiccation survival in Drosophila melanogaster. Heredity (Edinb)., 106: 68-77. doi: 10.1038/hdy.2010.40.

Fox, J., and W. Sanford. 2011. car: An R Companion to Applied Regression (R package).

Fox, J., and S. Weisberg. 2019. An R Companion to Applied Regression. Sage publications.

Fukui, S., S. L. May-McNally, E. B. Taylor, and I. Koizumi. 2018. Maladaptive secondary sexual characteristics reduce the reproductive success of hybrids between native and non-native salmonids. Ecol. Evol., 8: 12173-12182. doi: 10.1002/ece3.4676.

Garrigan, D., S. B. Kingan, A. J. Geneva, P. Andolfatto, A. G. Clark, K. R. Thornton, and D. C. Presgraves. 2012. Genome sequencing reveals complex speciation in the Drosophila simulans clade. Genome Res. 22:1499-1511.

Gibbs, A. G. 1998. Water-proofing properties of cuticular lipids. Am. Zool., 38: 471-482. 
doi: 10.1093/icb/38.3.471.

Gibbs, A. G., and S. Rajpurohit. 2010. Cuticular lipids and water balance. P. in Insect Hydrocarbons Biology, Biochemistry, and Chemical Ecology.

Gleason, J. M., R. A. James, C. Wicker-Thomas, and M. G. Ritchie. 2009. Identification of quantitative trait loci function through analysis of multiple cuticular hydrocarbons differing between Drosophila simulans and Drosophila sechellia females. Heredity (Edinb)., 103: 416-424. doi: 10.1038/hdy.2009.79.

Gleason, J. M., and M. G. Ritchie. 2004. Do Quantitative Trait Loci (QTL) for a courtship song difference between Drosophila simulans and $D$. sechellia coincide with candidate genes and intraspecific QTL? Genetics 166:1303-1311.

Godoy-Herrera, R., B. Burnet, and K. Connolly. 2005. Hybrid disadvantage in the larval foraging behaviour of the two neotropical species of Drosophila pavani and Drosophila gaucha. Genetica, 124: 33-40. doi: 10.1007/s10709-004-5913-8.

Gottsberger, B., and F. Mayer. 2007. Behavioral sterility of hybrid males in acoustically communicating grasshoppers (Acrididae, Gomphocerinae). J. Comp. Physiol. A Neuroethol. Sensory, Neural, Behav. Physiol., 7: 703-714. doi: 10.1007/s00359007-0225-y.

Gottsberger, B., and F. Mayer. 2019. Dominance effects strengthen premating hybridization barriers between sympatric species of grasshoppers (Acrididae, Orthoptera). J. Evol. Biol., 32: 921-930. doi: 10.1111/jeb.13490.

Grillet, M., C. Everaerts, B. Houot, M. G. Ritchie, M. Cobb, and J. F. Ferveur. 2012. Incipient speciation in Drosophila melanogaster involves chemical signals. Sci. Rep. 2:224, doi: 10.1038/srep00224.

937 Harrison, R. G. 2012. The language of speciation. Evolution. 66:3643-3657.

938 Harrison, R. G., and E. L. Larson. 2014. Hybridization, introgression, and the nature of species boundaries. Journal of Heredity. 105(S1): 795-809. 
940 Hercus, M. J., and A. A. Hoffmann. 1999. Desiccation resistance in interspecific Drosophila crosses: Genetic interactions and trait correlations. Genetics. 151: 1493-1502.

Higgie, M., and M. W. Blows. 2008. The evolution of reproductive character displacement conflicts with how sexual selection operates within a species. Evolution 62: 1192-1203. doi: 10.1111/j.1558-5646.2008.00357.x.

Higgie, M., S. Chenoweth, and M. W. Blows. 2000. Natural selection and the reinforcement of mate recognition. Science 290: 519-521. doi: 10.1126/science.290.5491.519.

Hothorn, A. T., A. Zeileis, G. Millo, and D. Mitchell. 2011. Package 'Imtest.' R News. Hothorn, T., F. Bretz, and P. Westfall. 2008. Simultaneous Inference in Genneral Parametric Models. Biometrical J. 50:346-363.

Hothorn, T., K. Hornik, M. A. Van De Wiel, and A. Zeileis. 2006. A lego system for conditional inference. Am. Stat. 60:257-263.

954 Ingleby, F. C. 2015. Insect cuticular hydrocarbons as dynamic traits in sexual 955 communication. Insects, 6: 732-742.

956 Ingleby, F. C., D. J. Hosken, K. Flowers, M. F. Hawkes, S. M. Lane, J. Rapkin, I. Dworkin, and J. Hunt. 2013. Genotype-by-environment interactions for cuticular hydrocarbon expression in Drosophila simulans. J. Evol. Biol., 26: 94-107. doi: 10.1111/jeb.12030.

Ippolito, A., G. W. Fernandes, and T. P. Holtsford. 2004. Pollinator preferences for Nicotiana alata, N. forgetiana, and their F1 hybrids. Evolution 58: 2634-2644. doi: 10.1111/j.0014-3820.2004.tb01617.x.

Irwin, D. E. 2019. Assortative mating in hybrid zones is remarkably ineffective in promoting speciation. Am. Nat., 195: E150-E167. Jallon, J.-M., and J. R. David. 1987. Variation in cuticular hydrocarbons among the eight species of the Drosophila melanogaster subgroup. Evolution, 41: 294-302. Assortative mating in animals and its role for speciation. Am. Nat., 194: 865-875. doi: $10.1086 / 705825$.

Kassambara, A., and F. Mundt. 2017. Package "factoextra" for R: Extract and Visualize 
971

972

973

974

975

976

977

978

979

980

981

982

983

984

985

986

987

988

989

990

991

992

993

994

995

996

997

998

999

1000

1001

the Results of Multivariate Data Analyses. R Package version 1.0. 4.

Kliman, R. M., P. Andolfatto, J. A. Coyne, F. Depaulis, M. Kreitman, A. J. Berry, J. McCarter, J. Wakeley, and J. Hey. 2000. The population genetics of the origin and divergence of the Drosophila simulans complex species. Genetics. 156: 1913-1931.

Kost, S., D. G. Heckel, A. Yoshido, F. Marec, and A. T. Groot. 2016. A Z-linked sterility locus causes sexual abstinence in hybrid females and facilitates speciation in Spodoptera frugiperda. Evolution, 70: 1418-1427. doi: 10.1111/evo.12940.

Krebs, R. A. 1990. Courtship behavior and cotrol of reproductive isolation in Drosophila mojavensis: Genetic analysis of population hybrids. Behav. Genet., 20: 535-543. doi: 10.1007/BF01067718.

Lachaise, D., J. R. David, F. Lemeunier, L. Tsacas, and M. Ashburner. 2018. The reproductive relationships of Drosophila sechellia with $D$. mauritiana, $D$. simulans, and D. melanogaster from the Afrotropical region. Evolution 40:262-271.

Lachaise, D., M. Harry, M. Solignac, F. Lemeunier, V. Bénassi, and M. L. Cariou. 2000. Evolutionary novelties in islands: Drosophila santomea, a new melanogaster sister species from São Tomé. Proc. R. Soc. London B Biol. Sci. 267:1487-1495.

Lenth, R., and M. Hervé. 2015. Ismeans: Least-Squares Means. R package version, 2(17).

Lenth, R.V., 2017. Using Ismeans. J Stat Softw, 69, pp.1-33.

Levin, D. A. 1970. The exploitation of pollinators by species and hybrids of Phlox. Evolution 24: 367-377. doi: 10.2307/2406811.

Liimatainen, J. O., and J. M. Jallon. 2007. Genetic analysis of cuticular hydrocarbons and their effect on courtship in Drosophila virilis and D. lummei. Behav. Genet., 37: 713-725. doi: 10.1007/s10519-007-9158-z.

Linn, C. E., H. R. Dambroski, J. L. Feder, S. H. Berlocher, S. Nojima, and W. L. Roelofs. 2004. Postzygotic isolating factor in sympatric speciation in Rhagoletis flies: Reduced response of hybrids to parental host-fruit odors. Proc. Natl. Acad. Sci. U. S. A., 101: 17753-17758. doi: 10.1073/pnas.0408255101.

Llopart, A. 2005. Multilocus Analysis of introgression between two sympatric sister species of Drosophila: Drosophila yakuba and D. santomea. Genetics 171:197210. 
1002 Llopart, A., D. Lachaise, and J. A. Coyne. 2009. An anomalous hybrid zone in

1003 Drosophila. 59: 2602-2607. dx.doi.org 59:2602.

1004 Mallet, J. 2005. Hybridization as an invasion of the genome. Trends Ecol. Evol. 20:229_ 1005237.

1006 Mallet, J., N. Besansky, and M. W. Hahn. 2016. How reticulated are species?

1007 BioEssays, 38: 140-149. doi: 10.1002/bies.201500149.

1008 Mas, F., and J. M. Jallon. 2005. Sexual isolation and cuticular hydrocarbon differences 1009 between Drosophila santomea and Drosophila yakuba. J. Chem. Ecol., 31: 27471010 2752. doi: $10.1007 /$ s10886-005-7570-5.

1011 Matute, D. R. 2010. Reinforcement of gametic isolation in Drosophila. PLoS Biol. 1012 8:e1000341.

1013 Matute, D. R. 2014. The magnitude of behavioral isolation is affected by characteristics 1014 of the mating community. Ecol. Evol. 4:2945-2956.

1015 Matute, D. R., and J. F. Ayroles. 2014. Hybridization occurs between Drosophila

Matute, D. R., and A. Harris. 2013. The influence of abdominal pigmentation on desiccation and ultraviolet resistance in two species of Drosophila. Evolution 67: 2451-2460. doi: 10.1111/evo.12122.

Mavárez J., C.A. Salazar, E. Bermingham, C. Salcedo, C.D., Jiggins and M. Linares. 2006. Speciation by hybridization in Heliconius butterflies. Nature. 441: 868-871. deficient in learning and memory. Evolution 72:1155-1164. doi: 10.1111/evo.13470.

Melo, M. C., C. Salazar, C. D. Jiggins, and M. Linares. 2009. Assortative mating preferences among hybrids offers a route to hybrid speciation. Evolution 63: 1660-

1032 Menzel, F., B. B. Blaimer, and T. Schmitt. 2017. How do cuticular hydrocarbons evolve? 
1033

1034

1035

1036

1037

1038

1039

1040

1041

1042

1043

1044

1045

1046

1047

1048

1049

1050

1051

1052

1053

1054

1055

1056

1057

1058

1059

1060

1061

1062

1063

Physiological constraints and climatic and biotic selection pressures act on a complex functional trait. Proc. R. Soc. B Biol. Sci., 284: 20161727. doi: 10.1098/rspb.2016.1727.

Mérot, C., B. Frérot, E. Leppik, and M. Joron. 2015. Beyond magic traits: Multimodal mating cues in Heliconius butterflies. Evolution. 69: 2891-2904. doi: 10.1111/evo.12789.

Moehring, A. J., J. Li, M. D. Schug, S. G. Smith, M. DeAngelis, T. F. C. Mackay, and J. A. Coyne. 2004. Quantitative trait loci for sexual isolation between Drosophila simulans and D. mauritiana. Genetics, 167: 1265-1274. doi: 10.1534/genetics.103.024364.

Moyle, L. C., M. S. Olson, and P. Tiffin. 2004. Patterns of reproductive isolation in three angiosperm genera. Evolution. 58: 1195-1208. doi: 10.1111/j.00143820.2004.tb01700.x.

Noor, M. A. F. 1997. Genetics of sexual isolation and courtship dysfunction in male hybrids of Drosophila pseudoobscura and Drosophila persimilis. Evolution. 51: 809815. doi: $10.2307 / 2411156$.

Nosil, P. 2012. Ecological Speciation. Oxford University Press;

Orr, H. A. 2005. The genetic basis of reproductive isolation: Insights from Drosophila. Proc. Natl. Acad. Sci. 102:6522-6526.

Orr, H. A., and D. C. Presgraves. 2000. Speciation by postzygotic isolation: Forces, genes and molecules. BioEssays. 22: 1085-1094.

Otte, T., M. Hilker, and S. Geiselhardt. 2018. Phenotypic plasticity of cuticular hydrocarbon profiles in insects. J. Chem. Ecol., 44: 235-247. doi: 10.1007/s10886018-0934-4.

Pfennig, K. S. 2007. Facultative mate choice drives adaptive hybridization. Science (80. )., 318: 965-967. doi: 10.1126/science.1146035.

Pinheiro J, Bates D, DebRoy S, S. D. and R. C. T. 2017. nlme: Linear and Nonlinear Mixed Effects Models. R package version 3.1-131, https://CRAN.Rproject.org/package=nlme. $\mathrm{R}$ Packag. version 3.1-131, https//CRAN.Rproject.org/package=nlme., doi: 10.1016/j.tibs.2011.05.003.

R Core Team. 2016. R Development Core Team. 
1064

1065

1066

1067

1068

1069

1070

1071

1072

1073

1074

1075

1076

1077

1078

1079

1080

1081

1082

1083

1084

1085

1086

Rabosky, D. L., and D. R. Matute. 2013. Macroevolutionary speciation rates are decoupled from the evolution of intrinsic reproductive isolation in Drosophila and birds. Proc. Natl. Acad. Sci. U. S. A., 110: 15354-15359. doi:

10.1073/pnas.1305529110.

Rajpurohit, S., R. Hanus, V. Vrkoslav, E. L. Behrman, A. O. Bergland, D. Petrov, J. Cvačka, and P. S. Schmidt. 2017. Adaptive dynamics of cuticular hydrocarbons in Drosophila. J. Evol. Biol., 30: 66-80. doi: 10.1111/jeb.12988.

Rosenblum, E. B., B. A. J. Sarver, J. W. Brown, S. Des Roches, K. M. Hardwick, T. D. Hether, J. M. Eastman, M. W. Pennell, and L. J. Harmon. 2012. Goldilocks meets Santa Rosalia: an ephemeral speciation model explains patterns of diversification across time scales. Evol. Biol., 39: 255-61. doi: 10.1007/s11692-012-9171-x.

Sasa, M. M., P. T. Chippindale, and N. A. Johnson. 1998. Patterns of postzygotic isolation in frogs. Evolution. 52: 1811-1820. doi: 10.2307/2411351.

Schardl, C. L., and K. D. Craven. 2003. Interspecific hybridization in plant-associated fungi and oomycetes: A review. Molecular Ecology, 12: 2861-2873.

Schmidt, E. M., and K. S. Pfennig. 2016. Hybrid female mate choice as a species isolating mechanism: Environment matters. J. Evol. Biol., 29: 865-869.doi: 10.1111/jeb.12818.

Schrider, D. R., J. Ayroles, D. R. Matute, and A. D. Kern. 2018. Supervised machine learning reveals introgressed loci in the genomes of Drosophila simulans and $D$. sechellia. PLoS Genet., 14: e1007341. doi: 10.1371/journal.pgen.1007341.

Selz, O. M., R. Thommen, M. E. Maan, and O. Seehausen. 2014. Behavioural isolation may facilitate homoploid hybrid speciation in cichlid fish. J. Evol. Biol., 27: 275-289. doi: 10.1111/jeb.12287.

Serrato-Capuchina, A., J. Wang, E. Earley, D. Peede, K. Isbell, and D. R. Matute. 2020. Paternally inherited P-element copy number affects the magnitude of hybrid dysgenesis in Drosophila simulans and D. melanogaster. Genome Biol. Evol., doi: 10.1093/gbe/evaa084.

Shahandeh, M. P., A. Pischedda, and T. L. Turner. 2018. Male mate choice via cuticular hydrocarbon pheromones drives reproductive isolation between Drosophila species. Evolution 72: 123-135. doi: 10.1111/evo.13389. 
1095 Sharma, M. D., C. Mitchell, J. Hunt, T. Tregenza, and D. J. Hosken. 2012. The genetics of cuticular hydrocarbon profiles in the fruit fly Drosophila simulans. J. Hered., 103(2), pp.230-239. doi: 10.1093/jhered/esr132.

1098

Shirangi, T. R., H. D. Dufour, T. M. Williams, and S. B. Carroll. 2009. Rapid evolution of sex pheromone-producing enzyme expression in Drosophila. PLoS Biol., 7: e1000168. doi: 10.1371/journal.pbio.1000168.

Singer, T. L. 1998. Roles of hydrocarbons in the recognition systems of insects. Am. Zool., 2: 394-405. doi: 10.1093/icb/38.2.394.

1103 Smadja, C., and R. K. Butlin. 2009. On the scent of speciation: The chemosensory 1104 system and its role in premating isolation. Heredity 102: 77-97.

Sobel, J. M., G. F. Chen, L. R. Watt, and D. W. Schemske. 2010. The biology of speciation. Evolution 64: 295-315.

1107 Svedin, N., C. Wiley, T. Veen, L. Gustafsson, and A. Qvarnström. 2008. Natural and sexual selection against hybrid flycatchers. Proc. R. Soc. B Biol. Sci., 275: 735-744. doi: 10.1098/rspb.2007.0967.

Taylor, S. A., and E. L. Larson. 2019. Insights from genomes into the evolutionary importance and prevalence of hybridization in nature. Nature Ecol. Evol. 3: 170177.

Thomas, M. L., and L. W. Simmons. 2011. Short-term phenotypic plasticity in long-chain cuticular hydrocarbons. Proc. R. Soc. B Biol. Sci., 278: 3123-3128 doi:

1116 Turelli, M., J. R. Lipkowitz, and Y. Brandvain. 2014. On the Coyne and Orr-igin of species: Effects of intrinsic postzygotic isolation, ecological differentiation, $X$ chromosome size, and sympatry on Drosophila speciation. Evolution, 68: 1176-

1123 Turissini, D. A., G. Liu, J. R. David, and D. R. Matute. 2015. The evolution of 1124 reproductive isolation in the Drosophila yakuba complex of species. J. Evol. Biol. 28:557-575. 
1126 Turissini, D. A., and D. R. Matute. 2017. Fine scale mapping of genomic introgressions within the Drosophila yakuba clade. PLoS Genet. 13:e1006971.

1128 Turissini, D. A., J. A. McGirr, S. S. Patel, J. R. David, and D. R. Matute. 2018. The rate of evolution of postmating-prezygotic reproductive isolation in Drosophila. Mol. Biol. Evol. 35:312-334.

1131 Vamosi, S. M., and D. Schluter. 1999. Sexual selection against hybrids between

1132 sympatric stickleback species: evidence from a field experiment. Evolution. 53: 874-

1133 879. doi: $10.2307 / 2640727$.

1134 Van Herrewege, J., and J. R. David. 1997. Starvation and desiccation tolerances in

1135 Drosophila: Comparison of species from different climatic origins. Ecoscience

$1136 \quad 4: 151-157$.

1137 Veltsos, P., C. Wicker-Thomas, R. K. Butlin, A. Hoikkala, and M. G. Ritchie. 2012.

1138 Sexual selection on song and cuticular hydrocarbons in two distinct populations of 1139 Drosophila montana. Ecol. Evol. 2: 80-94., doi: 10.1002/ece3.75.

1140 Venard, R., and J. M. Jallon. 1980. Evidence for an aphrodisiac pheromone of female

1141 Drosophila. Experientia, 36: 211-213. doi: 10.1007/BF01953737.

1142 Vortman, Y., A. Lotem, R. Dor, I. Lovette, and R. J. Safran. 2013. Multiple sexual

1143 signals and behavioral reproductive isolation in a diverging population. Am. Nat.,

1144 182: 514-523. doi: 10.1086/671908.

1145 Xue, H. J., K. A. Segraves, J. Wei, B. Zhang, R. E. Nie, W. Z. Li, and X. K. Yang. 2018.

1146 Chemically mediated sexual signals restrict hybrid speciation in a flea beetle.

1147 Behav. Ecol., 29: 1462-1471.doi: 10.1093/beheco/ary105.

1148 Yukilevich, R. 2012. Asymmetrical patterns of speciation uniquely support

1149 reinforcement in Drosophila. Evolution 66:1430-1446. 